\title{
Amostragem intencional
}

\author{
Cátia Yumi Nagae
}

\author{
DisSERTAÇÃO APRESENTADA \\ $\mathrm{AO}$ \\ Instituto de Matemática e Estatística \\ DA \\ UNiVERSidAdE DE SÃo PAUlO \\ PARA \\ OBTENÇÃO DO TÍTULO \\ $\mathrm{DE}$ \\ Mestre em CiênCIAS
}

\author{
Área de Concentração: Estatística \\ Orientador: Prof. Dr. Carlos Alberto de Bragança Pereira
}

São Paulo, outubro de 2007 


\section{Amostragem intencional}

Este exemplar corresponde à redação final da dissertação/tese devidamente corrigida e defendida por Cátia Yumi Nagae e aprovada pela Comissão Julgadora.

Banca Examinadora:

- Prof. Dr. Carlos Alberto de Bragança Pereira (orientador) - IME-USP.

- Profa. Dra. Airlane Pereira Alencar - IME-USP.

- Prof. Dr. Francisco Louzada Neto - UFSCar. 


\section{Agradecimentos}

Ao Professor Carlinhos, que durante todas as etapas da elaboração desta dissertação esteve sempre presente e disposto.

Ao Marcelo Lauretto pela atenção e apoio que foram fundamentais para a realização deste trabalho.

Aos meus pais André e Alice, que me mostraram desde cedo a importância da educação.

Aos meus irmãos o incentivo e a dedicação que me deram nos momentos decisivos.

Ao Adriano Massuia pela disposição que mostrou em me ajudar a encontrar bibliografia sobre programação linear.

À Universidade de São Paulo e ao Instituto de Matemática e Estatística pela oportunidade concedida de aperfeiçoar meus estudos. 


\section{Resumo}

Neste trabalho apresentamos o método de amostragem intencional via otimização. Tal método baseia-se na fundamentação de que devemos controlar a seleção amostral sempre que houver conhecimento suficiente para garantir boas inferências de quantidades conhecidas e de alguma forma correlacionadas com aquelas desconhecidas e de interesse. Para a resolução dos problemas de otimização foram utilizadas técnicas de programação linear. Três aplicações foram apresentadas e em todas elas notou-se que o procedimento de amostragem intencional produziu amostras com bom balanceamento entre as composições amostrais e de referência.

Palavras-chave: amostragem, intencional, otimização. 


\begin{abstract}
In this work we present the method of intentional sampling by optimization. Such method is based on the fact that we must control the sampling selection whenever we have enough knowledge to guarantee good inferences of known quantities and somehow correlated with those interesting and unknown ones. Linear programming techniques were used to solve the optimization problems. Three applications were presented and all of them produced samples with good balancing properties related to the referenced populations.
\end{abstract}

Keywords: sampling, intentional, optimization. 


\section{Sumário}

Lista de Abreviaturas $\quad$ ix

Lista de Símbolos

Lista de Figuras

Lista de Tabelas $\quad$ xv

1 Introdução 1

2 Amostragem $\quad 3$

2.1 Sistemas de Referência . . . . . . . . . . . . . . . . . . . . . . 3

2.2 Tipos de Amostras . . . . . . . . . . . . . . . . . . . . 3

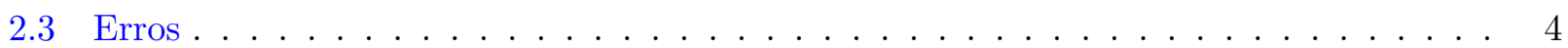

2.4 Métodos Usuais de Amostragem . . . . . . . . . . . . . . . . . . 5

2.4.1 Amostragem Aleatória Simples . . . . . . . . . . . . . . . . . 5

2.4 .2 Amostragem Estratificada . . . . . . . . . . . . . . . . . . . . 5

2.4 .3 Amostragem Sistemática . . . . . . . . . . . . . . . . . 6

2.4.4 Amostragem por Conglomerados . . . . . . . . . . . . . . . . 7

3 Motivação do Estudo $\quad 9$ 
4 Programação Linear $\quad 13$

4.1 Introdução . . . . . . . . . . . . . . . . . . . . . . . . 13

4.2 Solução Geométrica . . . . . . . . . . . . . . . . . . . 16

4.3 Método Simplex . . . . . . . . . . . . . . . . . . . 21

4.3 .1 Algoritmo Simplex . . . . . . . . . . . . . . . . 22

4.3 .2 Etapas do Método . . . . . . . . . . . . . . . . 26

4.4 Programação Linear Inteira . . . . . . . . . . . . . . . . . . . . . . . 28

4.4 .1 Branch and Bound . . . . . . . . . . . . . . 31

5 Resultados do Plano Amostral de Escolas $\quad 35$

6 Outras Aplicações $\quad 39$

6.1 Plano Amostral para Medição de Audiência de TV . . . . . . . . . . . . . . . . . . 39

6.2 Alocação Dinâmica . . . . . . . . . . . . . . . . . . . . . . 46

7 Considerações Finais $\quad 51$

A Plano Amostral de Escolas $\quad 53$

A.1 Municípios Participantes da Pesquisa . . . . . . . . . . . . . . . . 53

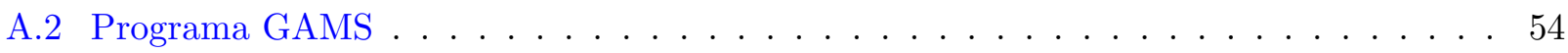

B Plano Amostral para Medição de Audiência de TV $\quad 59$

B.1 Programa GAMS . . . . . . . . . . . . . . . . . . . . 59

$\begin{array}{ll}\text { Referências Bibliográficas } & 63\end{array}$

$\begin{array}{ll}\text { Índice Remissivo } & 65\end{array}$ 


\section{Lista de Abreviaturas}

UC Unidade Censitária (Census Unit).

IBGE Instituto Brasileiro de Geografia e Estatística (Brazilian Institute of Geography and Statistics).

PNAD Pesquisa Nacional por Amostra de Domicílios (National Research by Households Sampling).

PIB Produto Interno Bruto (Gross Domestic Product). 


\title{
Lista de Símbolos
}

\author{
$\Re^{n} \quad$ Espaço real de dimensão $n$. \\ a Coeficientes tecnológicos. \\ $b \quad$ Requisitos mínimos. \\ c Coeficiente de custo. \\ $x \quad$ Variável de decisão. \\ $Q(x) \quad$ Função objetivo. \\ $z \quad$ Valor da função objetivo. \\ $x_{B} \quad$ Solução básica. \\ $x_{N B}$ Solução não básica.
}




\section{Lista de Figuras}

3.1 Distribuição de alunos da $2^{\mathrm{a}}$ série segundo Grupo UNICEF . . . . . . . . . . . . . . 10

3.2 Distribuição de alunos da $2^{\text {a }}$ série segundo rede de ensino. . . . . . . . . . . . . . . 11

3.3 Distribuição de alunos da $2^{\mathrm{a}}$ série segundo zona. . . . . . . . . . . . . . . . . 11

4.1 Separação de semi-planos no $\Re^{2} \ldots \ldots \ldots \ldots \ldots \ldots \ldots \ldots$

4.2 Separação de semi-espaços no $\Re^{3} \ldots \ldots \ldots \ldots \ldots \ldots$

4.3 Representação gráfica do exemplo numérico - Programação Linear. . . . . . . . . . . . 20

4.4 Representação gráfica do exemplo numérico - Programação Linear Inteira. . . . . . . . 29

4.5 Representação gráfica do exemplo numérico (Passo 1) . . . . . . . . . . . . . . . . 32

4.6 Representação gráfica do exemplo numérico (Passo 2) . . . . . . . . . . . . . . . . . 33

4.7 Representação gráfica do exemplo numérico (Passo 3) . . . . . . . . . . . . . . . 33

5.1 Distribuição de alunos da $2^{\mathrm{a}}$ série segundo Grupo UNICEF . . . . . . . . . . . . 37

5.2 Distribuição de alunos da $2^{\mathrm{a}}$ série segundo rede de ensino . . . . . . . . . . . 37

5.3 Distribuição de alunos da $2^{\mathrm{a}}$ série segundo zona . . . . . . . . . . . . . . 38

6.1 Esquema do processo de seleção. . . . . . . . . . . . . . . . . . . . . . 41

6.2 Distribuição de salário mínimo f . . . . . . . . . . . . . . . . . . . . 44

6.3 Distribuição de mulheres por faixa etária . . . . . . . . . . . . . . . . . 44 
6.4 Distribuição de homens por faixa etária . . . . . . . . . . . . . . . . . 45

6.5 Distribuição de pessoas acima de 10 anos por anos de estudo . . . . . . . . . . . . . 45

6.6 Distribuição de pessoas por horas diárias de tv . . . . . . . . . . . . . . . . . 46 


\section{Lista de Tabelas}

2.1 Tipos de Amostra. . . . . . . . . . . . . . . . . . . . . . 4

6.1 Erros Amostrais. . . . . . . . . . . . . . . . . . . . . 46

6.2 Medida de desbalanceamento entre os tratamentos. . . . . . . . . . . . . . . . 49

A.1 Municípios participantes da pesquisa. . . . . . . . . . . . . . 53 


\section{Capítulo 1}

\section{Introdução}

A amostragem é uma etapa de grande relevância no planejamento de um estudo. O uso de um procedimento amostral inadequado para o estudo pode levar a uma tendência nos resultados e, assim, provocar interpretações equivocadas.

Usualmente definimos uma "boa" amostra como aquela que é representativa, ou seja, a que é uma microrepresentação do universo. Porém, para saber se uma amostra é representativa com relação a uma dada característica de interesse, é necessário conhecer o comportamento desta característica na população. Assim, o conhecimento da população seria tão grande que se tornaria desnecessária a coleta da amostra. Desta forma, não se sabe a priori se uma determinada amostra é "boa" ou "ruim", e torna-se obrigação do planejador tentar escolher aquela amostra que menos dê indícios de ser inadequada.

Dependendo do tipo de estudo e da técnica utilizada, a amostra pode não refletir a estrutura da população de onde foi retirada e, por isso, seus resultados não podem ser estendidos para a população. Segundo Bolfarine e Bussab (2005) [10], uma "boa" amostra permite a generalização de seus resultados dentro de limites aceitáveis de dúvidas. O problema nesse ponto é: como saber que uma determinada amostra permite a generalização para a população, da qual não se conhece os valores que se quer "inferenciar"?

Para se construir um plano de amostragem é necessário que as unidades amostrais estejam bem definidas, que o tamanho da amostra esteja estabelecido, que o tipo de procedimento de seleção das unidades esteja bem determinado, enfim, que os objetivos tais como custos por unidade amostral, tempo de coleta, parâmetros a serem estimados, precisão e erros máximos de estimativas estejam bem definidos e controlados. 
Apesar de a amostragem fazer parte da atividade diária da maioria das pessoas em muitas áreas do conhecimento, seu uso "racional" é restrito. Como conseqüência, muitas vezes, uma amostragem mal conduzida acaba implicando em custo elevado da pesquisa e resultados tendenciosos.

Fica claro, portanto, a importância de se ter uma amostragem eficiente, evitando com isso desperdício de tempo e de recursos que acabam onerando a pesquisa e diminuindo o poder da inferência a partir dos seus resultados.

Esta dissertação tem como objetivo descrever um método de seleção amostral, utilizando-se técnicas estatísticas e de otimização. Será apresentado um delineamento de experimento no qual a utilização de técnicas de amostragem usuais poderiam produzir estimativas inadequadas, mesmo para parâmetros cujos valores são conhecidos. Nos casos onde estes parâmetros conhecidos estão fortemente correlacionados com os desconhecidos a qualidade da amostra é facilmente questionada.

A fundamentação que norteia a apresentação deste trabalho é a de que devemos controlar a seleção amostral sempre que haja conhecimento suficiente para garantir boas inferências de quantidades conhecidas e de alguma forma correlacionadas com aquelas desconhecidas e de interesse. A componente aleatória fica por conta da seleção dentro dos grupos que sofreram o controle pelo conhecimento dos parâmetros correlatos. 


\section{Capítulo 2}

\section{Amostragem}

Entendemos por amostragem a disciplina que estabelece regras metodológicas de seleção de subconjuntos, denominados amostras, de uma população. A escolha do método de seleção depende dos objetivos do estudo e das características populacionais que se quer estimar ou inferir. O objetivo da seleção amostral é justamente este, a realização de inferências sobre características populacionais, com base apenas na amostra selecionada e nas eventuais suposições distribucionais sobre estas características. Este capítulo é dedicado ao estabelecimento de conceitos utilizados na literatura.

\section{$2.1 \quad$ Sistemas de Referência}

A obtenção de uma amostra, qualquer que seja o plano amostral adotado, necessita de uma relação das unidades populacionais que definem a população objetivo para análise. O ideal seria dispor de um rol seqüencial destas unidades populacionais para viabilizar uma escolha conveniente das unidades que iriam compor a amostra, as unidades amostrais.

Raramente dispomos de tais informações, mas há algumas alternativas para descrever a relação das unidades como, por exemplo, os Censos e as PNADs. Estas fontes que descrevem o universo a ser investigado formam o chamado sistema de referências.

\subsection{Tipos de Amostras}

Jessen (1978) [12] propõe um modelo para identificar tipos de amostras, usando o cruzamento de dois fatores. O primeiro fator indica a presença ou ausência de um mecanismo probabilístico no plano de seleção da amostra, enquanto o segundo indica a existência ou não de um procedimento objetivo na seleção da amostra. 
Entende-se como procedimento objetivo aquele que quando utilizado por pessoas distintas produz a mesma amostra, ou uma amostra com as mesmas propriedades definidas previamente. Um procedimento subjetivo é aquele que permite ao usuário usar seus julgamentos para selecionar uma amostra, que em sua opinião é uma "boa" amostra.

\begin{tabular}{|c|c|l|}
\hline Critério de Amostrador & Seleção Probabilística & Seleção Não Probabilística \\
\hline \hline Objetivo & Amostras Probabilísticas & Amostras Criteriosas \\
Subjetivo & Amostras Quase Aleatórias & Amostras Intencionais \\
\hline
\end{tabular}

Tabela 2.1: Tipos de Amostra.

A combinação dos dois critérios permite criar os quatro tipos de planos amostrais identificados acima.

O método de amostragem apresentado nesta dissertação envolve conhecimento prévio sobre características populacionais que, de alguma forma, estão relacionadas àqueles parâmetros ou características que se quer estudar. Em resumo, tratamos de casos onde há conhecimento prévio de características populacionais que se relacionam fortemente com as quantidades populacionais (desconhecidas) de interesse para o estudo. Em nosso caso, a subjetividade é parcial, pois existe um consenso geral sobre esta informação: existência do forte relacionamento entre as características conhecidas e as que se quer conhecer. Com relação ao procedimento de seleção, cada elemento da população tem uma chance de ser selecionado para compor a amostra, mas a probabilidade de seleção depende da relação entre as características da unidade amostral e da população em estudo, já que o procedimento de seleção utiliza técnicas de otimização.

\section{$2.3 \quad$ Erros}

Nenhum plano de amostragem pode garantir que as decisões corretas serão sempre tomadas, isso porque é sempre considerada apenas uma parcela da população em questão. Mas, como o levantamento de toda a população é, em geral, impossível, muito dispendiosa ou destrutiva, toleramse os riscos de se tomarem decisões erradas.

Dessa forma, todo levantamento amostral está sujeito a produzir diferenças entre o parâmetro populacional de interesse e o seu valor estimado, tal diferença é denominada erro da pesquisa. Há dois grupos de fatores que podem agir sobre esta diferença:

- erros amostrais; 
- erros não amostrais;

O erro amostral é o desvio devido somente ao processo amostral e tende a desaparecer com o crescimento do tamanho da amostra. O erro não amostral é aquele proveniente de problemas de mensuração e de obtenção de informações, permanecendo mesmo em censos populacionais.

Segundo Bolfarine e Bussab (2005) [10], a qualidade do levantamento está associada à capacidade do pesquisador em evitar os erros, ou se não for possível, procurar manter esta diferença em níveis aceitáveis.

\subsection{Métodos Usuais de Amostragem}

Nesta seção faremos uma breve descrição dos métodos usuais de amostragem com o simples objetivo de permitir que o leitor perceba a diferença entre as técnicas tradicionais e o método proposto nos próximos capítulos.

\subsubsection{Amostragem Aleatória Simples}

A amostragem aleatória simples, como o próprio nome diz, é a mais simples de todas as técnicas. Além de servir como um plano amostral, o seu procedimento é utilizado de modo repetido em procedimentos de múltiplos estágios. Consiste na seleção de $n$ unidades amostrais de tal forma que cada unidade populacional tenha a mesma chance de ser escolhida.

Como principais vantagens, a amostragem aleatória simples requer mínimo conhecimento antecipado da população, livre de possíveis erros de classificação e facilita a análise de dados e cálculos de erros. Suas desvantagens são que o conhecimento que o pesquisador possa ter sobre o problema em estudo é desprezado e que para o mesmo tamanho de amostra, os erros são mais amplos do que a amostragem estratificada [7].

\subsubsection{Amostragem Estratificada}

A amostragem estratificada consiste na partição de uma população em grupos (estratos) segundo alguma(s) característica(s) conhecida(s) na população sob estudo e de cada um desses estratos são selecionadas amostras em proporções convenientes [10]. Normalmente, a variabilidade dentro dos extratos é menor do que a variabilidade entre os extratos, com respeito àquelas quantidades que definiram a partição da população. 
A estratificação é utilizada principalmente para resolver alguns problemas como a melhoria da precisão das estimativas, produzir estimativas para a população toda e subpopulações e problemas de custo, já que, mantendo-se a mesma precisão desejada de uma amostra aleatória simples, o tamanho da amostra estratificada é consideravelmente menor. Além disso, estimativas eficientes podem ser obtidas tanto globalmente como para cada um dos extratos.

A amostra estratificada é indicada quando a população é muito heterogênea e as razões de custo limitam o tamanho da amostra. Com uma precisão desejável, a amostra aleatória simples, por si só, na maioria das vezes é inviável. A partição da população em estratos, internamente mais homogêneos, pode solucionar o problema, mantendo-se a precisão desejada com uma amostra viável de tamanho consideravelmente menor [13].

O resultado será mais eficaz quanto maior for a habilidade do pesquisador em identificar estratos homogêneos. Uma simples estratificação por si só pode não produzir necessariamente amostras mais eficientes do que a amostragem aleatória simples. O conhecimento a priori de quantidades populacionais, relacionadas àquelas de interesse, é necessário para uma boa estratificação.

Segundo Cochran (1977) [7], como vantagens podem-se citar a segurança da representatividade com respeito às características utilizadas na definição dos estratos, garantindo, portanto precisão, menor variabilidade do que a amostragem aleatória, e a decrescente possibilidade de excluir unidades populacionais no processo seletivo. Podem ser analisadas características de cada estrato e serem feitas comparações. São desvantagens da estratificação a necessidade de informação acurada acerca da proporção de população em cada estrato; se não houver listas estratificadas disponíveis, prepará-las poderia ser dispendioso e, haveria a possibilidade de ocorrência de classificação errônea e, portanto, de aumento do viés ao estimar a variância.

\subsubsection{Amostragem Sistemática}

A amostragem sistemática usa a ordem natural, selecionando-se um ponto de partida aleatoriamente e a partir daí compõe-se a amostra segundo intervalos correspondentes ao número escolhido $(k)$. Por exemplo, considere uma população com $N$ elementos onde $N=k n$, e onde $k$ é um número inteiro. Considere também que a população está ordenada de 1 a $N$, formando o sistema de referências. Uma unidade é então selecionada aleataoriamente entre as $k$ primeiras unidades do sistema de referências. As unidades seguintes que farão parte da amostra são obtidas a partir da primeira unidade selecionada em intervalos de comprimento $k$. 
Como principal vantagem pode-se citar a simplicidade de coleta da amostra, permitindo fácil verificação. Já com relação às desvantagens, se a população apresenta tendências ou periodicidade pode-se super (ou sub) estimar a variância do estimador obtido a partir da amostragem sistemática.

Segundo Cochran (1977) [7], tanto a amostragem sistemática quanto a amostragem estratificada são muito mais eficientes do que a amostragem aleatória simples, mas a amostragem sistemática é menos precisa do que a amostragem estratificada.

\subsubsection{Amostragem por Conglomerados}

$\mathrm{Na}$ amostragem aleatória por conglomerados a população é dividida em subpopulações (conglomerados) distintas como quarteirões, residências, famílias, etc. Embora a primeira intenção seja utilizar os elementos como unidades amostrais, verifica-se em muitos levantamentos, que não há uma discriminação confiável dos elementos da população e que organizá-los seria muito dispendioso. Em outras situações, mesmo dispondo de uma relação das unidades, motivos de ordem econômica podem indicar a escolha de unidades amostrais maiores. Assim, há situações em que o plano amostral por conglomerados pode produzir amostras com menor custo para uma variância aceitável [7].

Alguns dos conglomerados são selecionados segundo a amostragem aleatória simples e todos os indivíduos nos conglomerados selecionados são observados. Porém, quando os conglomerados são muito homogêneos, não é recomendável observar todos os indivíduos, pois como as unidades são muito parecidas, elas trarão o mesmo tipo de informação, aumentando a variação amostral. Esse tipo de inconveniência fica claro se imaginarmos a situação limite em que todos os elementos do conglomerado são iguais. Bastaria conhecer a informação de uma unidade para conhecermos todo o conglomerado. Assim, uma medida para aumentar a eficiência da amostra sem aumentar seu tamanho é subsortear elementos dentro do conglomerado.

Segundo Bolfarine e Bussab (2005) [10], em geral, este método é menos eficiente do que a amostragem estratificada ou a aleatória simples, mas por outro lado, é bem mais econômica. 


\section{Capítulo 3}

\section{Motivação do Estudo}

Este capítulo apresenta o estudo que serviu de motivação para o desenvolvimento do método de amostragem intencional via otimização.

Desejava-se selecionar escolas para compor uma amostra de alunos da $2^{\mathrm{a}}$ série, para a aplicação de testes "de avaliação educacional" com o intuito de mensurar o nível de leitura e de escrita no sistema de ensino do Estado do Ceará. O conjunto de escolas selecionadas, e de classes em cada uma dessas escolas, deveria resultar em uma amostra de estudantes com composição semelhante, em suas diversas nuanças (variáveis que em nossa opinião estão relacionadas com o poder de aprendizagem dos estudantes), à da população em estudo.

Todas as turmas das escolas selecionadas realizaram as provas.

O exame deveria ser realizado em 49 municípios pré-definidos (Apêndice A.1). Para que as inferências resultantes da avaliação das provas retratassem fidedignamente, em nossa opinião, o perfil da população do estado do Ceará, tomamos como referência as distribuições de alunos da $2^{\mathrm{a}}$ série dentro do Estado e do conjunto dos 49 municípios, segundo as três variáveis abaixo:

1. Grupo UNICEF ao qual o município pertence: O UNICEF desenvolve o Programa "Selo UNICEF - Município Aprovado" [18], onde ocorre a certificação dos municípios do Estado do Ceará que se destacam nos cuidados para a melhoria da qualidade de vida de crianças e adolescentes. Para garantir que nenhum município seja prejudicado, recebendo metas cujo cumprimento esteja acima de suas capacidades financeiras e técnicas, os participantes são agrupados segundo os recursos que possuem, num total de cinco grupos. São utilizados como base para constituição de cada um dos cinco grupos de municípios: taxa de urbanização; média de 
anos de estudo dos chefes de domicílio; percentual de domicílios com abastecimento de água adequado; percentual de domicílios com esgotamento sanitário; percentual de domicílios com rendimento médio mensal do chefe de família superior a um salário mínimo; percentual de domicílios unipessoais (com um morador); percentual de domicílios com sete moradores ou mais; percentual do Produto Interno Bruto (PIB) do município com relação ao PIB do estado; e percentual de domicílios cujo chefe de família é do sexo feminino;

2. Rede de ensino (Municipal / Estadual);

3. Zona (Rural / Urbana).

O objetivo do plano amostral foi determinar o conjunto de escolas que atendesse às restrições e cujas proporções nas diversas categorias dessas três variáveis fossem as mais próximas possíveis da população.

Comparando as distribuições populacionais de alunos dos 49 municípios participantes com aquelas verificadas em todo o estado (sistema de referência), nota-se que as distribuições de freqüências são muito diferentes, em especial na variável Grupo UNICEF (Figura 3.1). Portanto, utilizandose técnicas tradicionais de amostragem, consideramos ser improvável a obtenção de amostras com composição, em relação as variáveis mencionadas, equivalentes às suas composições populacionais, totalmente conhecidas.

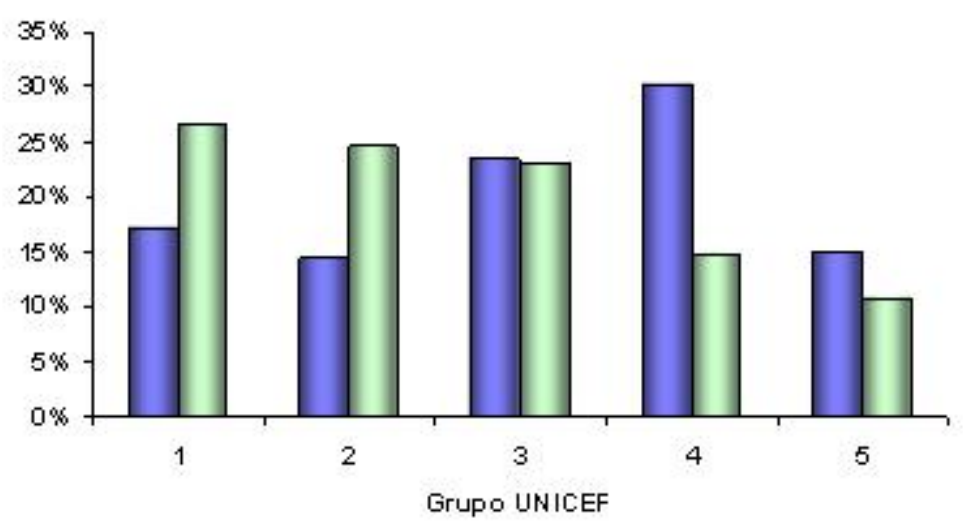

DEstado CE 口Municípios Participantes

Figura 3.1: Distribuição de alunos da $2^{\mathrm{a}}$ série segundo Grupo UNICEF. 


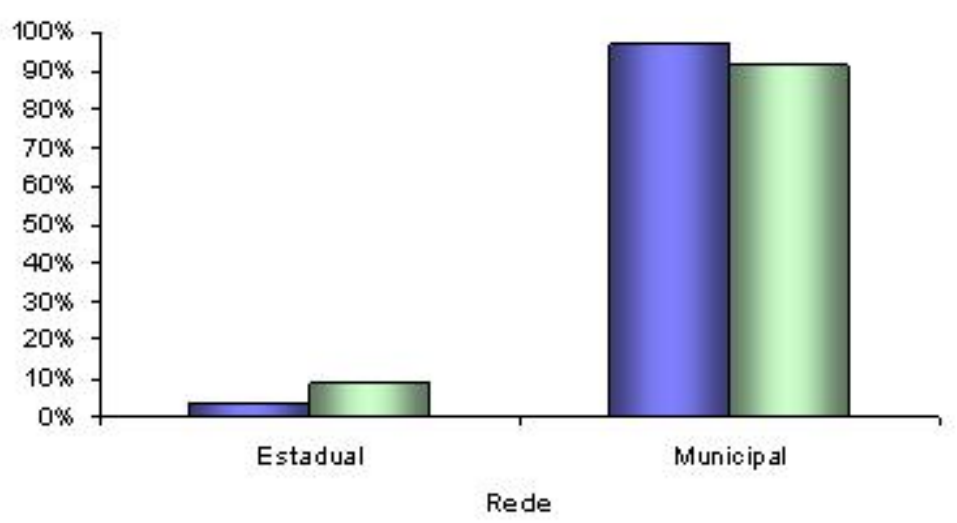

口Estado CE QMunicípios Participantes

Figura 3.2: Distribuição de alunos da $2^{\mathrm{a}}$ série segundo rede de ensino.

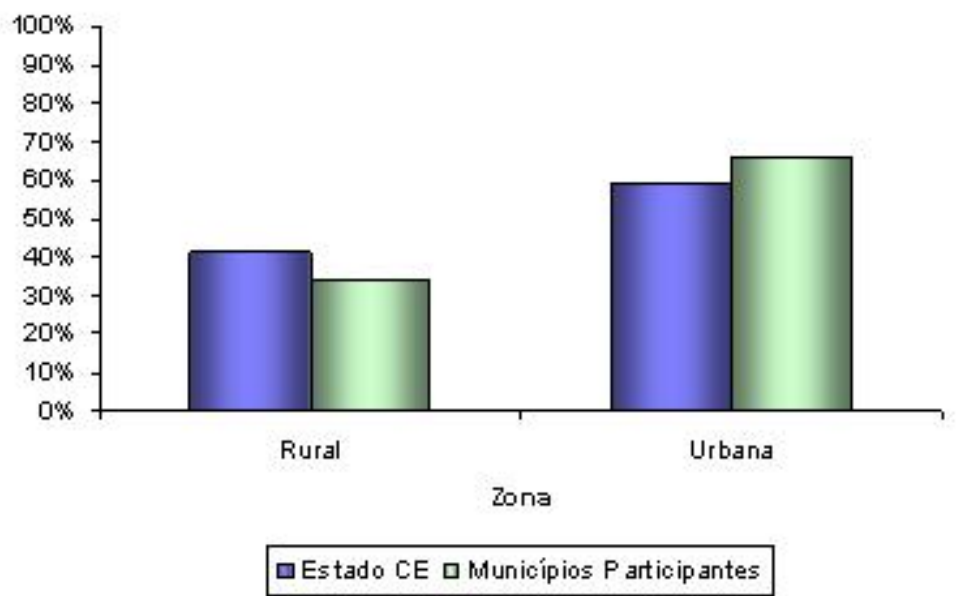

Figura 3.3: Distribuição de alunos da $2^{\mathrm{a}}$ série segundo zona. 
Devido às razões expostas acima, decidiu-se por um processo de otimização de seleção de escolas. A idéia é que a amostra deve ter a composição o mais próxima possível da composição populacional para aquelas variáveis consideradas neste processo de seleção. Lembrando que estas variáveis de seleção devem, em nossa opinião, ser as mais associadas às que vão proporcionar a avaliação dos estudantes.

Nos capítulos seguintes são descritos o método de otimização utilizado e os resultados da composição da amostra selecionada via amostragem intencional. 


\section{Capítulo 4}

\section{Programação Linear}

Para aplicação do método de amostragem intencional foram utilizadas técnicas de programação linear para solucionar os problemas de otimização. Este capítulo apresenta os principais conceitos sobre problemas de programação linear e seus métodos de resolução mais utilizados.

\subsection{Introdução}

A produção industrial, o fluxo de recursos na economia, o esforço militar na guerra e o gerenciamento de finanças são exemplos que requerem a coordenação de atividades inter-relacionadas. Estes casos compartilham da necessidade de se definir um conjunto de ações a serem tomadas de tal forma que esses sistemas estejam os mais próximos possíveis das metas desejadas.

Nestes sistemas, apesar de possuírem objetivos diferentes, os processos e a magnitude dos esforços envolvidos, quando modelados em termos teóricos, apresentam estruturas matemáticas notavelmente similares. Em particular, estes exemplos podem ser modelados por sistemas matemáticos de equações e inequações lineares, denominados modelos de programação linear [9].

A primeira e mais rentável aplicação de programação linear na indústria ocorreu no ramo petrolífero, incluindo a extração do petróleo, refino e distribuição. A indústria alimentícia também é uma grande usuária do advento da programação linear, seu primeiro uso ocorreu na alocação de meios de transporte de poucas plantações para muitos armazéns. Algumas empresas alimentícias utilizam a programação linear para determinar a combinação mais econômica de ingredientes na produção de salsichas e ração para animais. O corte de papel para a produção de caixotes e outros artefatos também exigiu que a indústria de papel fizesse da programação linear uma forte aliada. Mais recentemente, a programação linear e suas extensões têm sido utilizadas no mercado financeiro como um instrumento 
para reduzir custos e aumentar lucros, especialmente na análise de portifólio e de crédito.

A programação linear pode ser vista como parte do desenvolvimento da teoria da decisão, possibilitando a oportunidade de se definirem objetivos e de traçar-se um caminho detalhado de passos a serem seguidos de forma a atingir tais metas. Nossas ações para tal são: formulação dos problemas reais em termos matemáticos (modelos), apresentar técnicas para solucioná-los (algoritmo) e desenvolver ferramentas para executar os passos dos algoritmos (hardwares e softwares).

Assim, podemos dizer, resumidamente, que a programação linear trata da alocação ótima de recursos escassos entre atividades alternativas. Para melhor ilustrar um problema de programação linear, considere o plano amostral apresentado no Capítulo 3 desta dissertação. Neste estudo desejava-se selecionar uma amostra de escolas que fosse proporcional à população analisada segundo as seguintes variáveis: grupo UNICEF ao qual o município pertence, tipo de rede de ensino da escola e zona na qual a escola se localiza. Além disso, só poderiam participar da amostra as escolas localizadas em um dos 49 municípios monitorados pelo UNICEF. Desta forma, o problema foi definir um plano amostral que minimizasse as diferenças de composições entre a amostra e a população, com respeito às variáveis estudadas. Simultaneamente, não poderiam descumprir as restrições de delineamento e política. Esse sistema pode ser representado por um modelo matemático de equações e inequações lineares (ver Capítulo 5).

A programação linear, pelo exposto, visa fundamentalmente a obtenção da melhor solução para problemas que tenham seus modelos representados por restrições definidas por expressões lineares. Consiste, de fato, na maximização ou minimização de uma função linear, denominada função objetivo, respeitando-se um sistema linear de igualdades ou desigualdades que recebe o nome de restrições do modelo [8].

No exemplo de amostragem, podemos ilustrar a função objetivo como sendo o balanceamento da amostra frente à população, ou seja, o objetivo é minimizar as diferenças entre a composição da amostra e da população em estudo, nas suas diversas nuanças de interesse. As restrições do modelo seriam, por exemplo, os recursos envolvidos como custo operacional, custo político, tamanho da amostra (pequeno e eficiente), etc.

As restrições determinam um conjunto de soluções viáveis. A melhor das soluções viáveis, isto é, aquela que maximiza ou minimiza a função objetivo denomina-se solução ótima. O objetivo da programação linear é encontrar a solução ótima. No exemplo de amostragem, a solução ótima seria a amostra que possui o comportamento mais próximo da população, respeitando-se as restrições de 
custo e delineamento.

Para a resolução de um problema de programação linear é necessário primeiramente modelar o sistema em temos matemáticos:

$$
\begin{gathered}
\sum_{j=1}^{n} a_{i j} x_{j}=b_{i} \text { onde } b_{i} \geq 0 \quad(i=1, \ldots, m) \\
x_{j} \geq 0 \quad(j=1, \ldots, n) \\
\sum_{j=1}^{n} c_{j} x_{j}=Q(x)
\end{gathered}
$$

Os dois primeiros conjuntos de equação referem-se às restrições do modelo. A segunda restrição denomina-se condição de não negatividade, pois na maioria dos problemas as variáveis representam quantidades físicas e por isso devem ser não negativas. A última equação representa a função objetivo, ou seja, a função a ser minimizada ou maximizada.

Os coeficientes $x_{1}, x_{2}, \ldots, x_{n}$ são as variáveis de decisão a serem determinadas e $c_{1}, c_{2}, \ldots, c_{n}$ são conhecidos como coeficientes de custo. Os coeficientes $a_{i j}$ são denominados coeficientes tecnológicos e $b_{1}, b_{2}, \ldots, b_{m}$ representam os requisitos mínimos a serem satisfeitos.

Segundo Dantzig (1998) [9], o problema acima está representado na forma padrão. Problemas representados nesta forma possuem o primeiro conjunto de restrições definido por igualdades. As restrições do problema de programação linear também podem ser representadas por inequações, quando não escritas na forma padrão. Vale ressaltar que através de manipulações matemáticas podemos transformar qualquer inequação ou desigualdade em uma equação se subtrairmos ou adicionarmos variáveis positivas denominadas variáveis de folga. Para melhor ilustrar considere:

$$
\sum_{j=1}^{n} a_{i j} x_{j} \leq b_{i} \Rightarrow \sum_{j=1}^{n} a_{i j} x_{j}+x_{n+1}=b_{i}
$$

Observe que o valor do lado esquerdo da desigualdade pode ser no máximo o valor do lado direito. Portanto, existe uma "folga" entre estes dois valores que é representada pela variável de folga $x_{n+1}$.

É importante lembrar que os modelos matemáticos devem representar satisfatoriamente bem a realidade do sistema analisado, pois as soluções obtidas serão soluções do modelo e não necessaria- 
mente do sistema estudado. Assim, as fases de formulação e modelagem matemática do problema são de fundamental importância.

Segundo Bazaraa (1977) [3], para representar um problema de otimização, como programação linear, devem ser consideradas algumas suposições:

- Proporcionalidade: Considerando a variável $x_{j}$, sua contribuição para o custo é $c_{j} x_{j}$ e sua contribuição para a i-ésima restrição é $a_{i j} x_{j}$. Isto significa que se $x_{j}$ é dobrada, então suas contribuições para o custo e para cada restrição também serão dobradas;

- Aditividade: Esta suposição garante que o custo total será a soma dos custos individuais, e que a contribuição da i-ésima restrição é a soma das contribuições individuais;

- Divisibilidade: Garante que as variáveis de decisão possam ser divididas em níveis fracionários de forma que valores não inteiros sejam permitidos nas variáveis de decisão;

- Determinístico: Os coeficientes $c_{j}, a_{i j}$ e $b_{i}$ são fixados deterministicamente. Qualquer elemento probabilístico ou estocástico inerente à demanda, custo, preço, recursos disponíveis e outros fatores são aproximadamente assumidos por esses coeficientes por meio de valores determinísticos equivalentes.

Note que, em amostragem, a suposição de divisibilidade nem sempre é satisfeita, uma vez que, dependendo do problema, as variáveis de decisão assumem somente valores inteiros. No caso do plano amostral de escolas, as variáveis de decisão: quantidade de municípios por Grupo UNICEF, quantidade de escolas por rede de ensino e quantidade de escolas por zona são variáveis que só podem assumir valores inteiros. Assim, para modelar este sistema será necessário aplicar técnicas de um ramo específico da programação linear, a programação linear inteira.

Antes de partirmos para o estudo da programação linear inteira, ilustraremos métodos de solução de problemas de programação linear, uma vez que a programação linear inteira é uma sub-classe da programação linear.

\subsection{Solução Geométrica}

Nesta seção descreveremos o procedimento geométrico para a resolução de um problema de programação linear. Embora este método seja viável apenas para problemas de pequenas dimensões, ele permitirá a visualização da resolução do problema de programação linear. 
No $\Re^{2}$, a equação da reta é da forma $a x+b y+c=0$ com $a, b, c \in \Re$. A reta separa o plano em dois semi-planos, representados pelas desigualdades $a x+b y+c>0$ e $a x+b y+c<0$. Veja a representação gráfica a seguir:

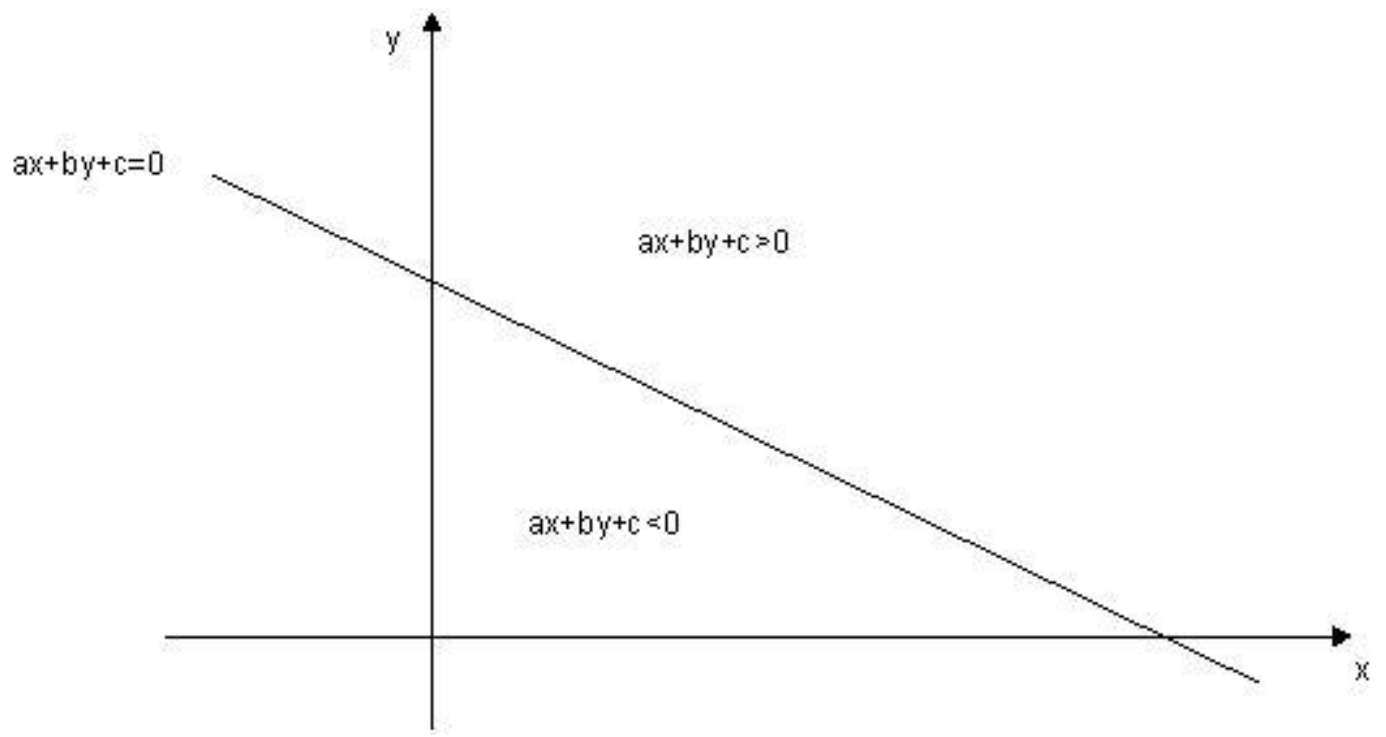

Figura 4.1: Separação de semi-planos no $\Re^{2}$.

No $\Re^{3}$, a equação do plano é da forma $a x+b y+c z+d=0 \operatorname{com} a, b, c, d \in \Re$. O plano separa o $\Re^{3}$ em duas regiões (semi-espaços), representados pelas inequações $a x+b y+c z+d>0 \mathrm{e}$ $a x+b y+c z+d<0$. A representação gráfica encontra-se a seguir. 


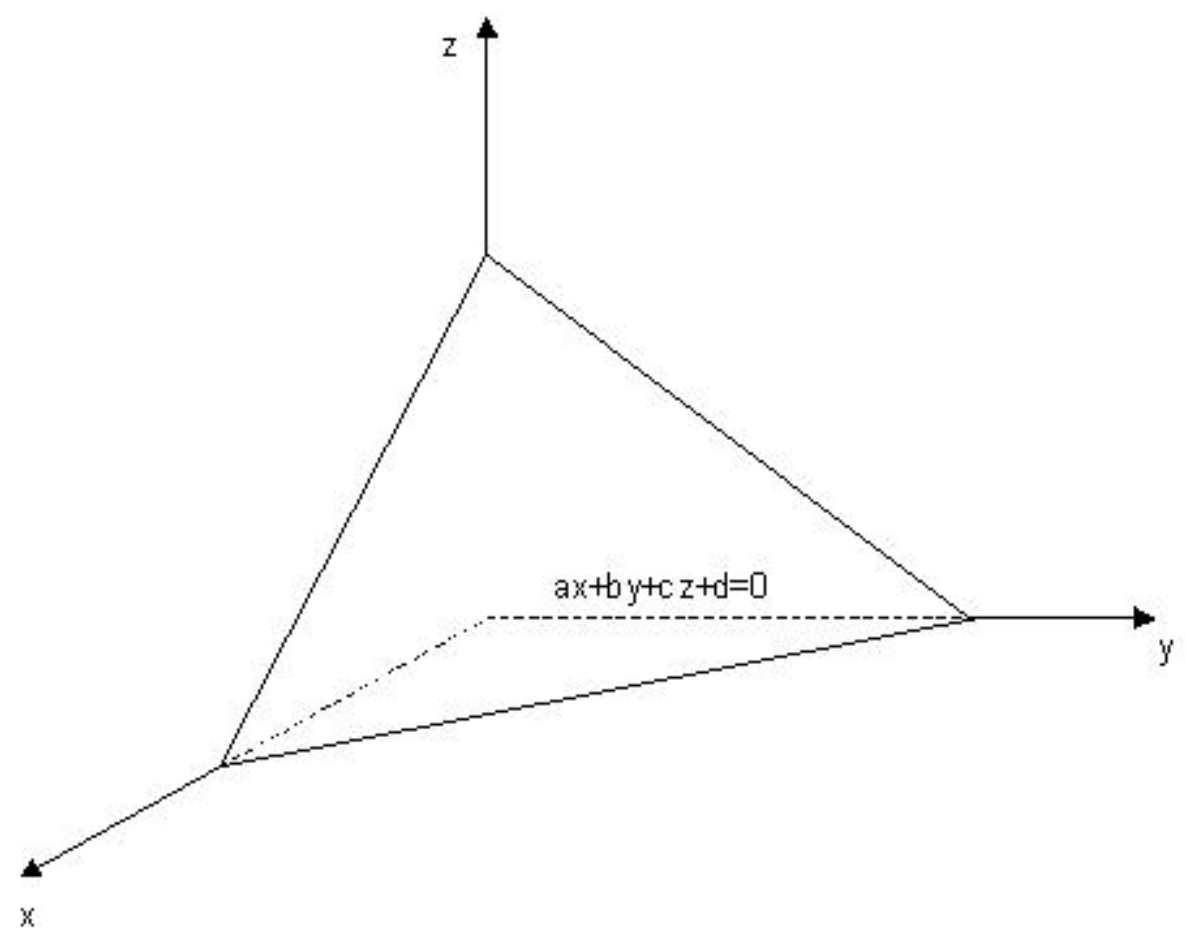

Figura 4.2: Separação de semi-espaços no $\Re^{3}$.

Estendendo para o $\Re^{n}$, podemos definir hiperplano como o conjunto de pontos da forma $\left(x_{1}, x_{2}, \ldots, x_{n}\right)$ tais que $a_{1} x_{1}+a_{2} x_{2}+\ldots+a_{n} x_{n}=a_{0} \operatorname{com}\left(a_{0}, a 1, \ldots, a_{n}\right) \in \Re$.

Como anteriormente, podemos dizer que o hiperplano divide em dois semi-espaços definidos pelas desigualdades $a_{1} x_{1}+a_{2} x_{2}+\ldots+a_{n} x_{n}>a_{0}$ e $a_{1} x_{1}+a_{2} x_{2}+\ldots+a_{n} x_{n}<a_{0}$.

Vimos na seção 4.1 que o problema de programação linear é dado por um conjunto de restrições do tipo:

$$
a_{i 1} x_{1}+a_{i 2} x_{2}+\ldots+a_{i n} x_{n}=b_{i}
$$

por condições de não negatividade:

$$
x_{j} \geq 0
$$


e por uma função objetivo:

$$
c_{1} x_{1}+c_{2} x_{2}+\ldots+c_{n} x_{n}=Q(x)
$$

Assim, fica evidente que as restrições (4.1) e as condições de não negatividade (4.2) podem ser representadas por um conjunto de hiperplanos e semi-espaços que determinarão um conjunto de pontos do espaço denominado conjunto de soluções viáveis. A função objetivo representa um conjunto de hiperplanos paralelos entre si. A cada ponto do conjunto de soluções viáveis está associado, um e somente um, hiperplano da família (4.3).

Graficamente, o problema de programação linear consiste, portanto, em encontrar, dentre o conjunto de soluções viáveis, delimitado pelos hiperplanos (4.1) e (4.2), aquele plano pelo qual passe um hiperplano da família (4.3) que otimize o valor $Q(x)$ a ele associado.

Como veremos graficamente, quando um problema de programação linear está na forma padrão e este possui solução ótima finita, então uma solução ótima sempre se encontra em um vértice ou ponto extremo. Cabe, portanto, procurar o vértice que otimize a função objetivo.

Veja a seguir um exemplo de resolução gráfica:

Restrições:

$$
\begin{gathered}
x_{1}+x_{2} \leq 6 \\
-x_{1}+2 x_{2} \leq 8
\end{gathered}
$$

Condições de não negatividade:

$$
x_{1}, x_{2} \geq 0
$$

Função objetivo:

$$
\text { Minimizar: }-x_{1}-3 x_{2}
$$

As restrições e condições de não negatividade determinam o conjunto de soluções viáveis, representado na Figura 4.3 (área cinza). As linhas tracejadas representam a função objetivo em vários pontos.

O objetivo é minimizar a função objetivo representada por $z=-x_{1}-3 x_{2}$. Fixando o valor de $z=0$, verificamos que a função objetivo pode ser representada pela reta tracejada que passa pela 


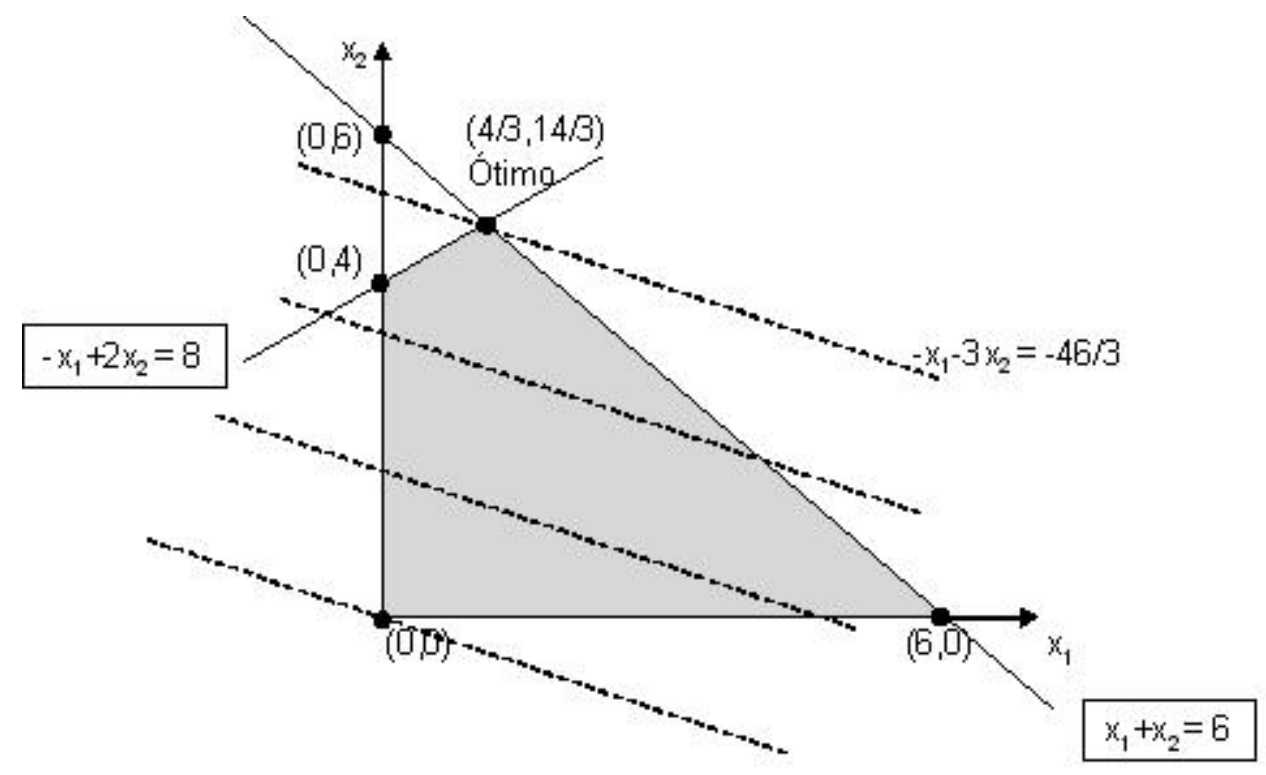

Figura 4.3: Representação gráfica do exemplo numérico - Programação Linear.

origem (Figura 4.3). Movendo esta reta, paralelamente, para cima e dentro da região de soluções viáveis, verificamos valores cada vez menores para $z$. Assim, encontramos a solução ótima no vértice $(4 / 3 ; 14 / 3)$.

O ponto ótimo também pode ser determinado por meio do gradiente (derivadas parciais) da função objetivo [8]. As derivadas parciais fornecem a taxa de variação da função objetivo em relação à variação marginal de cada uma das variáveis.

No caso de minimização, o sentido em que a função objetivo decresce é o oposto indicado pelo gradiente. Para melhor ilustrar considere a função objetivo do exemplo acima:

$$
z=-x_{1}-3 x_{2}
$$

Como o exemplo trata de uma minimização multiplicamos por (-1) a função objetivo $z$. O gradiente desta função é dado por:

$$
\frac{\partial f}{x_{1}}=1 \quad \text { e } \frac{\partial f}{x_{2}}=3
$$


Podemos interpretar os resultados da seguinte forma:

- se $x_{1}$ tem acréscimo em uma unidade, mantendo-se $x_{2}$ constante, a função objetivo diminui em 1 unidade;

- se $x_{2}$ tem acréscimo em uma unidade, mantendo-se $x_{1}$ constante, a função objetivo diminui em 3 unidades.

Em qualquer ponto $P\left(x_{1}, x_{2}\right)$ o gradiente é perpendicular ao local geométrico dos pontos do espaço onde a função tem o mesmo valor que tem em $P$, ou seja, o gradiente da função é perpendicular às retas de nível da função e indica a direção e sentido em que a função aumenta ou diminui mais rapidamente. Pode, portanto, identificar o ponto ótimo no conjunto de soluções viáveis.

Neste exemplo havia uma única solução ótima, mas dependendo da estrutura do problema alguns casos podem apresentar várias soluções ótimas diferentes ou ainda não possuir solução ótima.

A importância do método gráfico não consiste somente em encontrar a solução do problema, mas também permitir a visualização do método algébrico. A próxima seção apresenta o método algébrico empregado nesta dissertação.

\subsection{Método Simplex}

Em programação linear o método mais utilizado para determinar uma solução é o método Simplex [6]. Desde sua criação em 1947, algumas variações foram propostas e outros novos algoritmos foram desenvolvidos, mas o método Simplex continua a ser uma ferramenta viável e popular na solução de problemas de programação linear. Sua vasta aceitabilidade deve-se principalmente à:

- Capacidade de modelar problemas de decisão complexos;

- Produzir soluções em um período de tempo razoável.

O método Simplex não encontra diretamente a solução ótima, mas determina soluções viáveis, cada vez melhores, até que, depois de um certo número de iterações, seja encontrada a ótima. Assim, mesmo no caso de um problema de pequenas dimensões, o número de iterações é tão grande que se torna inviável resolvê-lo manualmente. Nesta dissertação foi utilizado o software GAMS [5] para resolução dos problemas de programação linear. 


\subsubsection{Algoritmo Simplex}

O algoritmo de resolução consiste em encontrar a solução ótima utilizando a técnica de pivoteamento. Para aplicação do algoritmo é necessário que o sistema esteja representado na forma padrão. Por exemplo, considere o seguinte problema de programação linear:

$$
\begin{gathered}
2 x_{1}+2 x_{2}+2 x_{3}+x_{4}+4 x_{5}=z \rightarrow \text { Minimizar } \\
4 x_{1}+2 x_{2}+13 x_{3}+\underline{3 x_{4}}+x_{5}=17 \\
x_{1}+x_{2}+5 x_{3}+x_{4}+x_{5}=7
\end{gathered}
$$

O pivoteamento consiste em escolher algum elemento diferente de zero (chamado pivô), assim como $\underline{3 x_{4}}$ e utilizá-lo de tal forma a eliminar $x_{4}$ das demais equações. Dividindo a equação do pivô por 3 obtemos:

$$
\begin{gathered}
\frac{4}{3} x_{1}+\frac{2}{3} x_{2}+\frac{13}{3} x_{3}+x_{4}+\frac{1}{3} x_{5}=\frac{17}{3} \\
-\frac{4}{3} x_{1}-\frac{2}{3} x_{2}-\frac{13}{3} x_{3}-\frac{1}{3} x_{5}+\frac{17}{3}=x_{4}
\end{gathered}
$$

Substituindo $x_{4}$ nas demais equações temos:

$$
\begin{array}{r}
\frac{2}{3} x_{1}+\frac{4}{3} x_{2}-\frac{7}{3} x_{3}+\frac{11}{3} x_{5}=z-\frac{17}{3} \\
\frac{4}{3} x_{1}+\frac{2}{3} x_{2}+\frac{13}{3} x_{3}+x_{4}+\frac{1}{3} x_{5}=\frac{17}{3} \\
-\frac{1}{3} x_{1}+\underline{\frac{1}{3} x_{2}}+\frac{2}{3} x_{3}+\frac{2}{3} x_{5}=\frac{4}{3}
\end{array}
$$

Se aplicarmos novamente este recurso, escolhendo $\underline{\underline{11} x_{2}}$ como pivô ( $2^{\mathrm{a}}$ restrição), obtemos:

$$
2 x_{1}-5 x_{3}+x_{5}=z-11
$$




$$
\begin{aligned}
& 2 x_{1}+3 x_{3}+x_{4}-x_{5}=3 \\
& -x_{1}+x_{2}+2 x_{3}+2 x_{5}=4
\end{aligned}
$$

Como o pivoteamento é um processo que insere e deleta equações redundantes, este não altera o conjunto de soluções. Assim, o sistema resultante (4.6) é equivalente ao sistema original (4.4).

Reescrevendo (4.6) temos:

$$
\begin{aligned}
& (-z)+2 x_{1}-5 x_{3}+x_{5}=-11 \\
& 2 x_{1}+3 x_{3}+x 4-x_{5}=3 \\
& -x_{1}+x_{2}+2 x_{3}+2 x_{5}=4
\end{aligned}
$$

O conjunto de equações acima se encontra na forma canônica em relação às variáveis $(-z), x_{4}, x_{2}$, que são denominadas variáveis dependentes, ou variáveis básicas, pois seus valores foram expressos em termos de variáveis independentes, ou variáveis não básicas [21].

Segundo Dantzig (1997) [9], um sistema de $m$ equações com $x_{j}$ variáveis é dito estar na forma canônica com relação a um conjunto ordenado de variáveis $\left(x_{j 1}, x_{j 2}, \ldots, x_{j m}\right)$ se e somente se $x_{j i}$ tem coeficiente unitário na i-ésima equação e zero nas demais.

A solução básica viável é encontrada igualando as variáveis não básicas à zero. No nosso exemplo temos:

$$
z=11 \quad x_{B}=\left(x_{2} ; x_{4}\right)=(3 ; 4) \quad x_{N B}=\left(x_{1} ; x_{3} ; x_{5}\right)=(0 ; 0 ; 0)
$$

Quando o valor de uma ou mais variáveis básicas é zero, diz-se que a solução básica é degenerada. $\mathrm{Na}$ ausência de degeneração, o algoritmo Simplex termina em um número finito de iterações. O fenômeno da degeneração pode implicar em não convergência do algoritmo Simplex. Neste exemplo, a solução básica é não degenerada.

A solução básica deve ser não negativa, pois este é um requisito necessário para utilização do método Simplex. 
Note que ao escolher $(-z)$ e o conjunto de variáveis básicas arbitrariamente, estas nem sempre fornecem uma solução básica viável. Por exemplo, utilizando as variáveis $x_{1}$ e $x_{4}$ como pivôs, a solução básica encontrada seria:

$$
z=3 \quad x_{B}=\left(x_{1} ; x_{4}\right)=(-4 ; 11) \quad x_{N B}=\left(x_{2} ; x_{3} ; x_{5}\right)=(0 ; 0 ; 0)
$$

A solução acima não é uma solução viável, pois $x_{1}$ é negativo.

Após encontrar a solução básica viável, deve-se encontrar a solução ótima, ou seja, a que minimiza o valor de $z$.

Note que a forma canônica (4.7) apresenta fator de custo negativo $\left(c_{3}=-5\right)$. Assim, quando aumentamos o valor de $x_{3}$, mantendo todas as demais variáveis não básicas iguais a zero e ajustando as variáveis básicas de tal forma que as equações permaneçam satisfeitas, é evidente que o valor de $z$ se reduzirá, pois

$$
z=11-5 x_{3}
$$

Parece razoável, portanto, aumentar o valor de $x_{3}$, pois assim $z$ ficará o menor possível. Entretanto, neste caso o valor de $x_{3}$ não pode ser aumentado indefinidamente, pois enquanto as demais variáveis não básicas sejam zero, os valores das variáveis básicas devem satisfazer:

$$
\begin{aligned}
& x_{2}=4-2 x_{3} \\
& x_{4}=3-3 x_{3}
\end{aligned}
$$

Assim, se $x_{3}$ assumir valor maior que $2, x_{2}$ terá valores negativos e se $x_{3}$ for maior que $1, x_{4}$ será negativo. Desta forma, o maior valor permitido é $x_{3}=1$, resultando em:

$$
z=6 \quad x_{B}=\left(x_{2} ; x_{3}\right)=(2 ; 1) \quad x_{N B}=\left(x_{1} ; x_{4} ; x_{5}\right)=(0 ; 0 ; 0)
$$

Note que se tivéssemos selecionado $3 x_{3}$ como sendo o pivô em (4.6), obteríamos a mesma solução. Também é possível verificar que a variável $x_{4}$ passou de básica para não básica, uma vez que, após a alteração, esta assume valor zero. 
Esta solução reduz $z$ de 11 para 6, mas ainda não sabemos se esta é a solução mínima. Assim, reescreveremos a forma canônica (4.7) utilizando as novas variáveis básicas $x_{2}$ e $x_{3}$ :

$$
\begin{aligned}
& (-z)+\frac{16}{3} x_{1}+\frac{5}{3} x_{4}-\frac{2}{3} x_{5}=-6 \\
& \frac{2}{3} x_{1}+x_{3}+\frac{1}{3} x_{4}-\frac{1}{3} x_{5}=1 \\
& -\frac{7}{3} x_{1}+x_{2}-\frac{2}{3} x_{4}+\frac{8}{3} x_{5}=2
\end{aligned}
$$

Note que o valor de $z$ ainda pode ser reduzido, uma vez que (4.8) apresenta fator de custo negativo $\left(c_{5}=-\frac{2}{3}\right)$ e não apresenta solução básica degenerada. Assim, mantendo as demais variáveis básicas iguais a zero e solucionando os novos valores de $x_{2}, x_{3}$ e $z$ em termos de $x_{5}$ :

$$
\begin{gathered}
-z=-6+\frac{2}{3} x_{5} \\
x_{3}=1+\frac{1}{3} x_{5} \\
x_{2}=2-\frac{8}{3} x_{5}
\end{gathered}
$$

Podemos reescrever a forma canônica (4.8) com as novas variáveis básicas:

$$
\begin{aligned}
& (-z)+\frac{19}{4} x_{1}+\frac{1}{4} x_{2}+\frac{3}{2} x_{4}=-\frac{11}{2} \\
& \frac{3}{8} x_{1}+\frac{1}{8} x_{2}+x_{3}+\frac{1}{4} x_{4}=\frac{5}{4} \\
& -\frac{7}{8} x_{1}+\frac{3}{8} x_{2}-\frac{1}{4} x_{4}+x_{5}=\frac{3}{4}
\end{aligned}
$$

Aumentando $x_{5}$ ao máximo e mantendo $x_{2}$ e $x_{3}$ não negativos encontramos a seguinte solução básica viável: 


$$
z=\frac{11}{2} \quad x_{B}=\left(x_{3} ; x_{5}\right)=\left(\frac{5}{4} ; \frac{3}{4}\right) \quad x_{N B}=\left(x_{1} ; x_{2} ; x_{4}\right)=(0 ; 0 ; 0)
$$

Como todos os fatores de custo são positivos, esta solução é a que minimiza $z$.

Foram necessárias 2 iterações de pivô no sistema canônico inicial (4.7) para encontrar a solução ótima.

Este exemplo ilustra os 2 componentes principais do algoritmo Simplex:

- Teste de otimização: se todos os fatores de custo são não negativos, a solução básica viável é ótima;

- Introdução de variáveis não básicas: quando acrescentamos variáveis não básicas, o total que podemos alterar o seu valor está restrito de tal forma que os valores ajustados das variáveis básicas permaneçam não negativos.

\subsubsection{Etapas do Método}

O método Simplex parte de uma solução básica viável inicial e se propõe a gerar novas soluções básicas cada vez melhores até encontrar uma que não possa mais ser melhorada (solução ótima).

Desta forma, o algoritmo apresentado na seção 4.3.1 é empregado em 2 etapas. Na primeira, busca-se uma solução básica viável inicial para iniciar a segunda fase ou para determinar que não há solução viável. Uma vez encontrada a solução inicial, a segunda etapa consiste em determinar a solução ótima ou a classe de soluções viáveis que minimizem ou maximizem a função objetivo [9].

Na fase 1, o primeiro passo é a introdução na forma padrão de termos adicionais, de tal maneira que o sistema resultante possa ser escrito na forma canônica. Estas variáveis são denominadas, por muitos autores, de variáveis artificiais. Vale ressaltar que estes termos não são variáveis legítimas, e são introduzidos somente para facilitar a inicialização do método Simplex. Entretanto, as variáveis artificiais devem, eventualmente, assumir valor igual à zero para garantir viabilidade do problema original.

Assim, o objetivo é substituir z (função objetivo) por $w$, onde $w$ é a soma das variáveis artificiais. Nesta primeira fase, o algoritmo Simplex, através de seqüências de operações de pivoteamento, produzirá diferentes formas canônicas sucessivas com a propriedade de que a soma das variáveis 
artificiais $(w)$ diminua a cada iteração, no caso de minimização.

Para exemplificar, considere o problema:

$$
\begin{gathered}
2 x_{1}+x_{2}+2 x_{3}+x_{4}+4 x_{5}=z \rightarrow \text { Minimizar } \\
4 x_{1}+2 x_{2}+13 x_{3}+3 x_{4}+x_{5}=17 \\
x_{1}+x_{2}+5 x_{3}+x_{4}+x_{5}=7
\end{gathered}
$$

Iniciamos a fase 1 adicionando as variáveis artificiais $x_{6} \geq 0$ e $x_{7} \geq 0$ e a função objetivo artificial $w:$

$$
\begin{gathered}
x_{6}+x_{7}=w \\
4 x_{1}+2 x_{2}+13 x_{3}+3 x_{4}+x_{5}+x_{6}=17 \\
x_{1}+x_{2}+5 x_{3}+x_{4}+x_{5}+x_{7}=7
\end{gathered}
$$

Caso exista uma solução básica viável para o sistema original (4.10) então esta mesma solução também satisfaz (4.11) com as variáveis artificiais iguais a zero, ou seja, $w=0$. Também segue que se o mínimo de $w$ for maior que zero, então não há solução viável para o sistema original. Assim, na primeira fase o objetivo é minimizar $w$ de forma similar à minimização de $z$, apresentada na seção 4.3.1. Além disso, o ideal é que as variáveis artificiais, ao final da primeira fase, devam ser consideradas não básicas e, portanto, inelegíveis ao pivoteamento na segunda etapa, evitando a reintrodução de variáveis artificiais na solução. Desta forma, a regra geral é tornar inelegível ao pivoteamento (na segunda fase) todas as variáveis, artificiais ou não, que tenham fatores de custo positivos na equação de $w$ (no caso de minimização).

Quando o sistema original possuir redundâncias ou quando ocorrerem soluções degeneradas, as variáveis artificiais permanecerão como parte do conjunto de variáveis básicas no final da primeira etapa. Assim, é necessário que seus valores durante a segunda fase nunca sejam maiores que zero.

Na fase 2, reintroduzimos a função objetivo $z$ e a minimizamos utilizando o algoritmo Simplex. 
Resumidamente, utilizamos variáveis artificiais para obter uma solução básica viável inicial e fazemos uso do algoritmo Simplex para eliminar as variáveis artificiais e solucionar o sistema original. Desta forma, o método Simplex se tornou uma ferramenta extremamente poderosa no planejamento prático de grandes sistemas complexos.

\subsection{Programação Linear Inteira}

Nos problemas de programação linear muitas vezes necessitamos que as variáveis assumam valores inteiros. Vimos na seção 4.1 que problemas de programação linear supõem continuidade no espaço de soluções, ou seja, assume-se que as variáveis de decisão possam ser divididas em níveis fracionários de forma que valores não inteiros sejam permitidos. Na prática são diversas as situações em que este pressuposto não é admissível, por exemplo, o plano amostral de escolas apresentado no Capítulo 3. Problemas desta natureza não podem ser solucionados utilizando os métodos usuais de programação linear, assim foi desenvolvida a área de programação linear inteira.

Um problema de programação linear em que todas as suas variáveis são discretas (devem assumir valores inteiros) é denominado problema de programação linear inteira pura. Quando somente algumas das variáveis estão sujeitas à essa condição estamos diante de um problema de programação linear inteira mista. Em outras situações, é necessário que as variáveis assumam valores binários (inteiros restringidos a 0 e 1) para exprimirem situações dicotômicas, neste caso trata-se de um problema de programação linear inteira binária [20].

Podemos considerar os problemas de programação linear inteira como uma sub-classe da programação linear. Assim, modelos de programação linear inteira são modelos de programação linear, sujeitos a restrições adicionais indicando que alguma ou todas as variáveis são inteiras, como no exemplo a seguir

Restrições:

$$
\begin{gathered}
x_{1}+x_{2} \leq 6 \\
-x_{1}+2 x_{2} \leq 8
\end{gathered}
$$




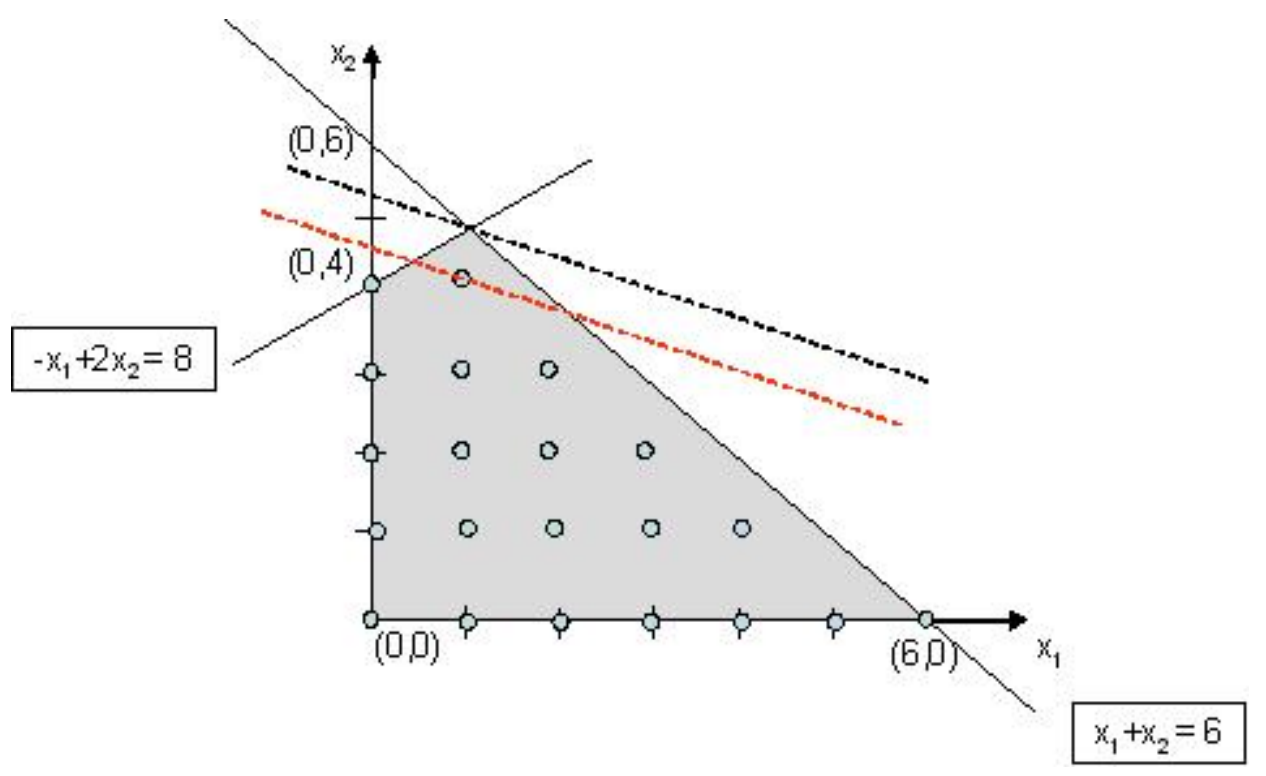

Figura 4.4: Representação gráfica do exemplo numérico - Programação Linear Inteira.

Condições:

$x_{1}, \quad x_{2} \geq 0$ e inteiros;

Função objetivo:

\section{Minimizar : $-x_{1}-3 x_{2}$}

Na Figura 4.4 a área em cinza representa o conjunto de soluções viáveis e os pontos representam as soluções viáveis inteiras. A linha preta tracejada representa a solução ótima, e a linha vermelha a solução ótima inteira. Vale ressaltar, que em problemas de programação linear, o ponto ótimo sempre se localiza no vértice. Porém, quando assumimos a restrição de valores inteiros, o ponto ótimo pode ou não ser extremo do espaço de soluções.

O valor da função objetivo no ponto ótimo inteiro é sempre "igual ou pior" do que o valor da função objetivo no ponto ótimo contínuo. Podemos dizer que a função objetivo no ponto ótimo do problema, desconsiderando a condição de que as variáveis devam assumir somente valores inteiros, 
representa:

- No caso de maximização o valor máximo que pode atingir a função objetivo no ponto ótimo inteiro;

- No caso de minimização o valor mínimo que pode atingir a função objetivo no ponto ótimo inteiro;

Os problemas de programação linear, como visto na seção 4.3, são solucionados de forma extremamente eficiente e, entre os problemas de programação linear e de programação linear inteira, a única diferença é haver, no caso da programação inteira, menos soluções a serem consideradas (soluções inteiras e não reais).

A simples introdução da restrição de não divisibilidade das variáveis em um problema de programação linear, transforma-o num sistema de características diferentes, ao qual devem ser aplicadas técnicas específicas de resolução. Remover as soluções possíveis não inteiras do problema dificulta sua resolução, pois eram essas soluções que garantiam a existência das soluções básicas (pontos extremos do conjunto de soluções viávies) e, assim, asseguravam a simplicidade e eficiência do método Simplex.

Quando um problema de programação linear inteira possui um número finito de soluções possíveis, a idéia de enumeração exaustiva pode surgir como uma abordagem simples e eficiente para a determinação da solução ótima. Porém, o número de soluções possíveis pode facilmente tornar-se demasiadamente grande, inviabilizando do ponto de vista computacional a sua enumeração exaustiva.

Poderíamos pensar que arredondando (para o inteiro mais próximo) os valores assumidos pelas variáveis restritas a valores inteiros, na solução do problema de programação linear, teríamos uma solução razoável. No entanto, apesar de sua simplicidade aparente, esta técnica não é recomendável, pois, utilizando a idéia de arredondamento, podemos nos afastar demasiadamente do ponto ótimo e a solução encontrada pode não ser admissível para o problema de programação linear inteira. Esta constatação não desmerece o interesse pela solução contínua, pois esta, considerada conjuntamente com as novas restrições, permite reduzir gradualmente o espaço de soluções viáveis e auxiliar na condução ao ponto ótimo.

Desta forma, para solucionar problemas de programação linear inteira são necessários métodos que examinem apenas uma parte do conjunto de soluções viáveis e que aproveitem as vantagens do algoritmo Simplex. 


\subsubsection{Branch and Bound}

O método Branch and Bound utiliza o algoritmo Simplex para determinar a solução ótima de problemas de programação linear cuja região de solução viável é reduzida até se alcançar a solução do problema de programação linear inteira. Assim, fica claro que a dificuldade do cálculo de uma solução inteira não é resultado da ineficiência do método Simplex, mas sim da descontinuidade do espaço de solução. Este método de resolução pode ser aplicado a qualquer modelo de programação linear inteira e foi utilizado nesta dissertação para solucionar os problemas de otimização.

Segundo Wolsey (1998) [20], quando a solução ótima de um problema de programação linear assume valores inteiros, temos que essa também é a solução ótima de um problema de programação linear inteira. Desta forma, ao modificar adequadamente o problema de programação linear inteira é possível atingir uma situação em que as soluções ótimas (contínua e inteira) coincidam.

Partindo do pressuposto acima, o método de Branch and Bound parte inicialmente da desconsideração da restrição de que as variáveis devam assumir valores inteiros. Assim, quando a solução do problema de programação linear assume valores inteiros, então a solução ótima do problema de programação linear inteira foi encontrada; caso contrário, divide-se o problema de programação linear em dois, através da introdução de restrições adicionais que fazem a partição do conjunto das soluções viáveis. Então são resolvidos sucessivos problemas de programação linear, estabelecendo-se limites para o valor ótimo da função objetivo e, assim, eliminando diversos subconjuntos, até se alcançar a solução ótima do problema de programação linear inteira.

Para melhor ilustrar considere o exemplo a seguir:

Restrições:

$$
\begin{gathered}
6 x_{1}+7 x_{2} \geq 84 \\
2 x_{1} \geq 10 \\
3 x_{2} \geq 6
\end{gathered}
$$

Condições:

$$
x_{1}, x_{2} \geq 0 \text { e inteiros; }
$$


Função objetivo:

$$
\text { Minimizar }: 6 x_{1}+8 x_{2}=z
$$

Por se tratar de um problema de minimização deve-se estabelecer um limite superior para o valor da função objetivo. Assim qualquer problema com solução inviável só é objeto de partição se apresentar valor da função objetivo inferior ao limite superior corrente.

Desconsiderando a restrição de que as variáveis devam assumir somente valores inteiros e aplicando o método Simplex, a solução ótima é:

$$
z=86 \quad x_{1}=\frac{35}{3} \quad x_{2}=2
$$

Como visto na seção 4.4 a solução do problema, considerando a restrição de assumir somente valores inteiros, pode ser no mínimo igual a 86. Note que o valor de $x_{1}$ não é um número inteiro, assim devemos dividir o problema em dois casos:

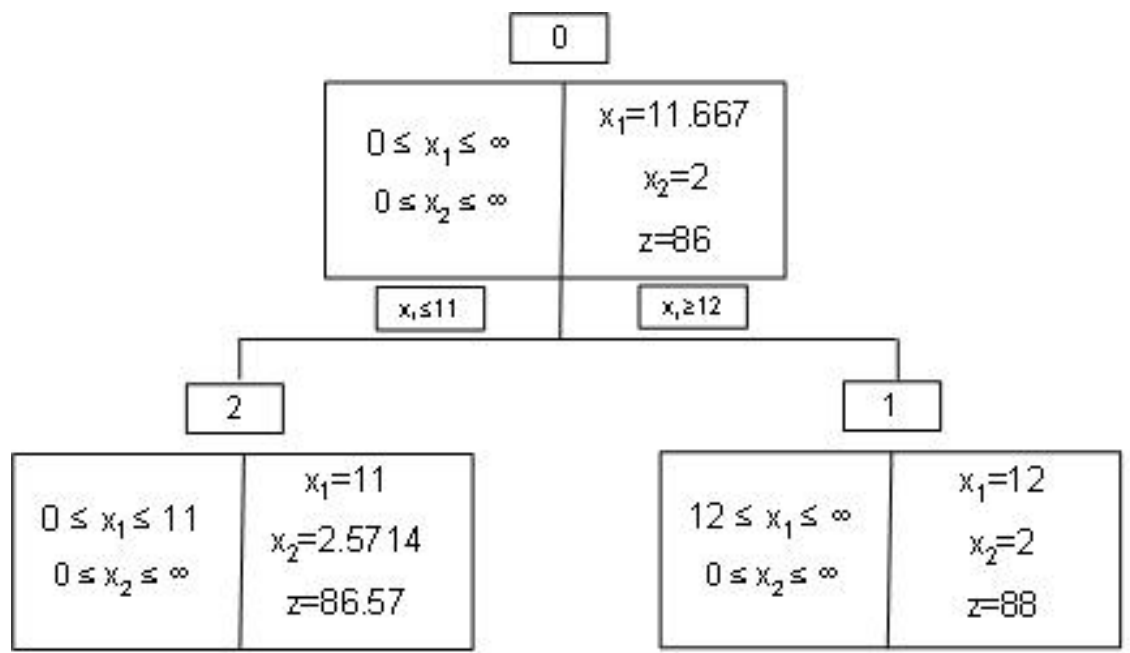

Figura 4.5: Representação gráfica do exemplo numérico (Passo 1).

O sub-problema 1 tem solução viável com $z=88$ que passa a ser o novo limite superior (problemas com $z>88$ não serão objeto de partição), uma vez que se trata de um problema de minimização. 
No sub-problema 2 notamos que $z=86.57$, ou seja, apresenta valor menor do que o limite de 88 . Assim, prosseguimos efetuando a partição na variável $x_{2}$ :

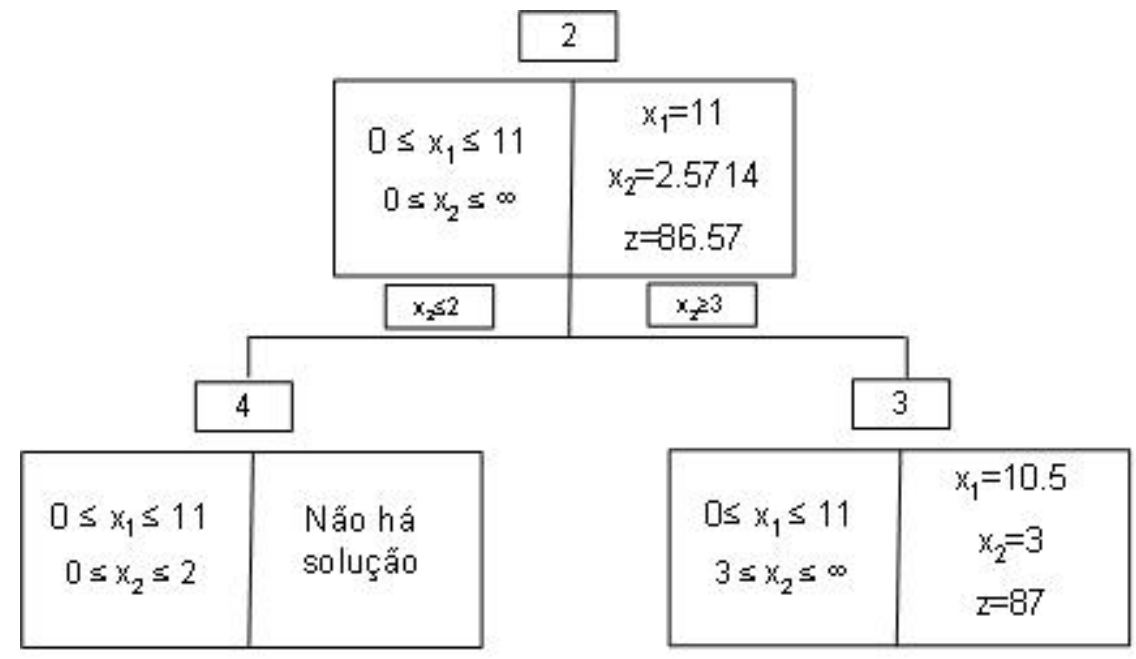

Figura 4.6: Representação gráfica do exemplo numérico (Passo 2).

O sub-problema 3 com $z=87$, inferior ao limite superior corrente (88) deve ser objeto de partição na variável $x_{1}$.

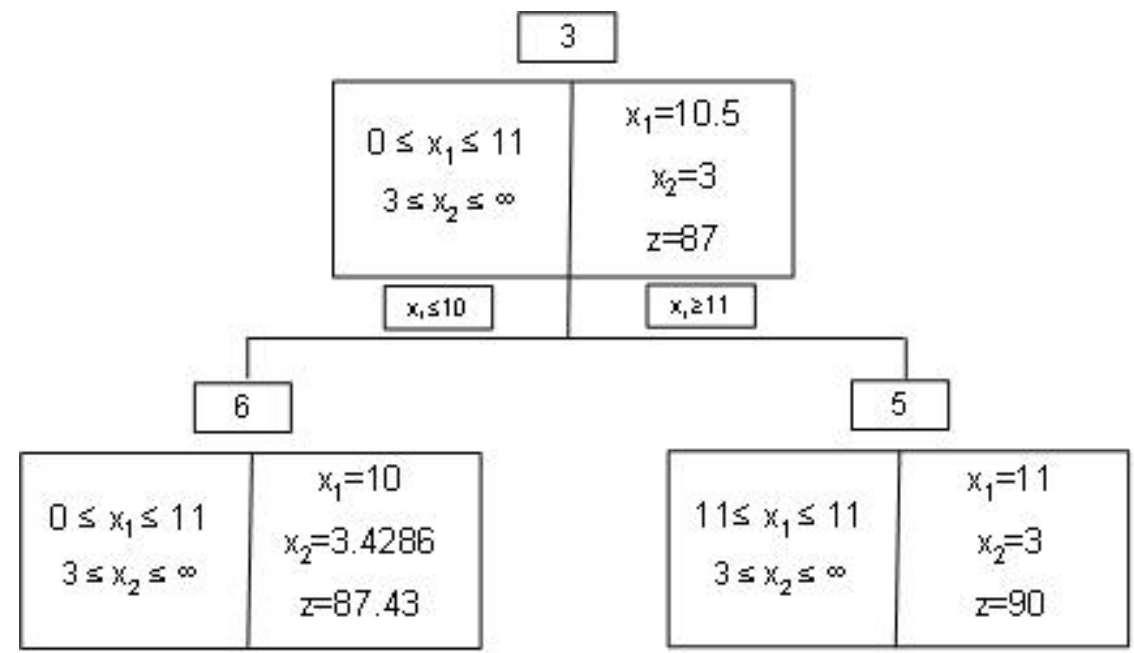

Figura 4.7: Representação gráfica do exemplo numérico (Passo 3). 
O sub-problema 5 possui solução viável, mas como $z$ é maior do o limite superior corrente (88) esta solução não é de interesse.

O sub-problema 6 possui $z=87.43$ que é inferior ao limite superior corrente. Assim, se sua partição resultar uma solução viável está terá, na melhor das hipóteses $z=88$, ou seja, valor igual ao já disponível.

Portanto, a solução ótima inteira é dada por:

$$
z=88 \quad x_{1}=12 \quad x_{2}=2
$$

Resumidamente, o método de Branch and Bound desenvolve uma "árvore", cuja raiz é a solução do problema de programação linear formado a partir do problema de programação linear inteira dado, retirando-lhe a restrição de assumir somente valores inteiros. Se a solução desse problema de programação linear for inteira, pararemos e teremos a solução ótima inteira; caso contrário, escolheremos uma variável $x_{k}$ cujo valor no ponto ótimo do problema de programação linear seja $x_{k}{ }^{*}$ não inteiro e resolveremos mais dois problemas de programação linear: o primeiro acrescentando a restrição $x_{k} \leq x_{k}{ }^{*}$ e o segundo a restrição $x_{k} \leq x_{k}{ }^{*}+1$. Este procedimento é repetido até encontrarmos uma solução inteira e garantirmos que seja ótima.

De um modo geral, o método de Branch and Bound é menos trabalhoso para resolver problemas de programação linear inteira, pois apresenta a vantagem de podermos interrompê-lo antes de encontrar a solução ótima e de dispor de uma solução inteira, em relação à qual se pode ter uma idéia de quão próxima estará da solução ótima graças aos limites que se vão determinando. 


\section{Capítulo 5}

\section{Resultados do Plano Amostral de Escolas}

Neste capítulo apresentamos a formulação do procedimento de amostragem intencional via programação linear inteira, bem como os resultados quantitativos da amostra de escolas para o estudo descrito no Capítulo 3.

O plano amostral tinha como objetivo selecionar um conjunto de escolas, dentro dos 49 municípios participantes, para aplicação de uma prova. Vimos no Capítulo 3 que técnicas usuais de amostragem poderiam produzir amostras desbalanceadas com relação às variáveis analisadas.

Assim, a solução adotada foi modelar a seleção de escolas como um problema de programação linear inteira, buscando fazer com que as proporções de alunos da amostra sob as variáveis analisadas fossem as mais próximas possíveis das proporções populacionais do Estado do Ceará.

Função objetivo:

$$
\text { Minimizar: } \sum_{j=1}^{m} w_{j}\left(p_{j}+q_{j}\right)+\sum_{i=1}^{n} x_{i}
$$

Restrição:

$$
\sum_{i=1}^{n} A_{i, j} x_{i}+p_{j}-q_{j}=d_{j}
$$

Condições:

$$
x_{i} \in\{0,1\}, \quad p_{j}, q_{j} \in Z^{+}, \quad i=1, \ldots, n, \quad j=1, \ldots, m
$$

Onde, 
$n=2557$ (total de escolas candidatas);

$m=10$ (total de categorias);

$x_{i}$ : Se a i-ésima escola foi selecionada $x_{i}=1$, senão $x_{i}=0$;

$w_{j}$ : Importância relativa (peso) da categoria $\mathrm{j}$ no processo de amostragem; permite que as variáveis tenham níveis diferentes de importância;

$p_{j}$ : Variável de folga;

$q_{j}$ : Variável de excesso;

$A_{i j}$ : Número de alunos da escola $i$ pertencentes à categoria $j$;

$d_{j}$ : Quantidade esperada de alunos do painel de escolas que deverão estar contidos na categoria $j$;

Note que a variável de decisão é o vetor binário $x$ com 2557 posições correspondentes às escolas candidatas a participar da pesquisa (escolas pertencentes a um dos 49 municípios participantes, com no mínimo 10 alunos da $2^{\text {a }}$ série). Cada elemento $x_{i}$ indica se a i-ésima escola foi ou não selecionada. Foram calculadas, a partir das distribuições de referência, as quantidades esperadas de alunos na amostra em cada categoria $\left(d_{j}\right)$. A variável de decisão $x$ foi determinada de forma a minimizar a função objetivo composta por duas parcelas ponderadas:

- A soma das diferenças absolutas (erros) entre as quantidades esperadas e as quantidades obtidas nas escolas selecionadas;

- O número total de escolas.

A segunda componente, número total de escolas, foi adotada como um refinamento do modelo: caso duas soluções distintas apresentem aproximadamente o mesmo resultado em termos de erro, é selecionada aquela com menor número de escolas.

O programa em GAMS encontra-se no Apêndice A.2.

Nas figuras abaixo nota-se que o procedimento de amostragem intencional produziu uma amostra bem semelhante à composição populacional para as variáveis analisadas. 


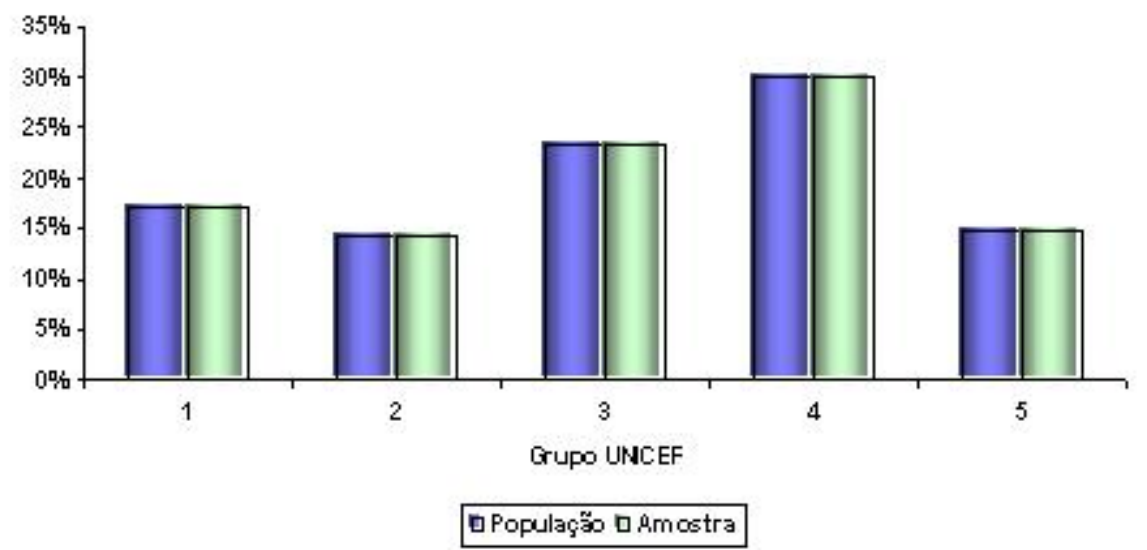

Figura 5.1: Distribuição de alunos da $2^{\mathrm{a}}$ série segundo Grupo UNICEF

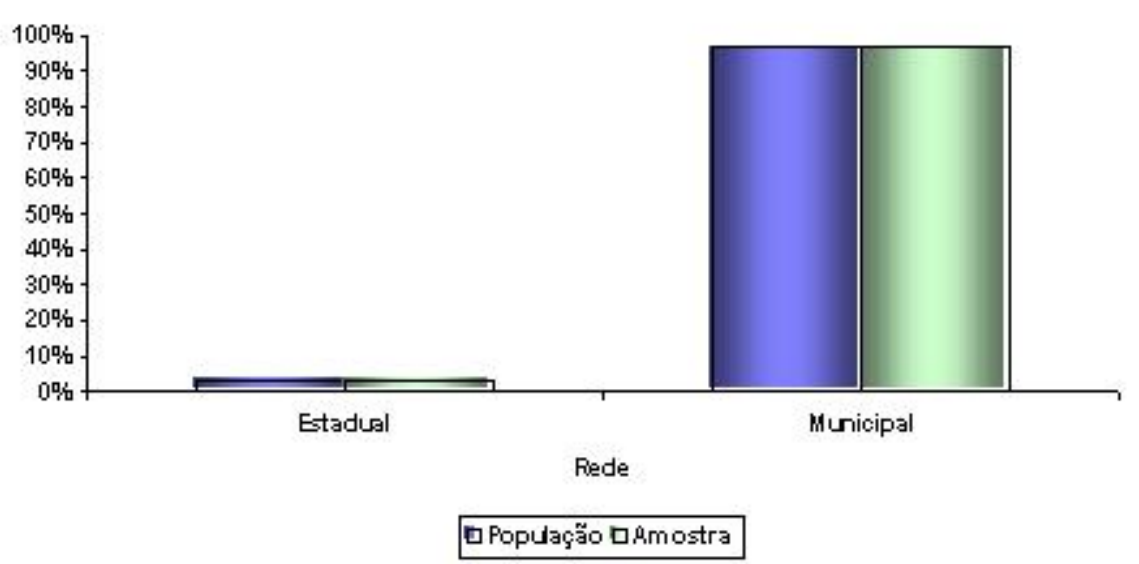

Figura 5.2: Distribuição de alunos da $2^{\mathrm{a}}$ série segundo rede de ensino

Para fornecer uma métrica de precisão em cada variável, definimos duas medidas de erro amostral:

- Erro esperado: é a soma ponderada dos erros das categorias, ponderada pelas freqüências populacionais. Essa medida fornece a sub-representação ou super-representação esperada para um indivíduo da população tomado ao acaso;

- Erro máximo: é o maior dos erros sobre as categorias. Esta é uma medida de pior caso: 


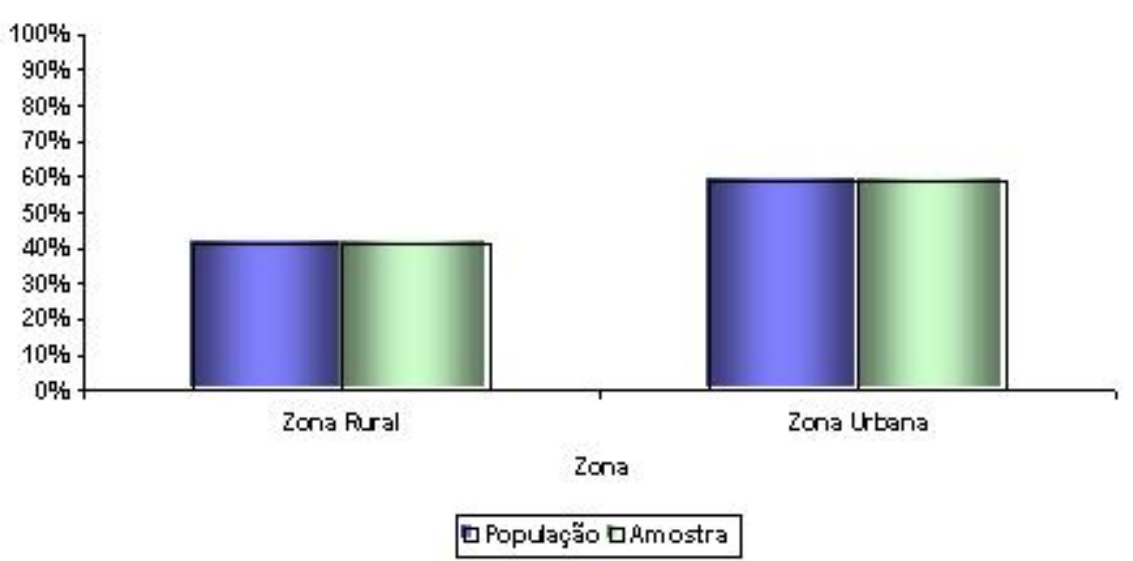

Figura 5.3: Distribuição de alunos da $2^{\mathrm{a}}$ série segundo zona

sub-representação ou super-representação de cada indivíduo da população.

$\mathrm{Na}$ amostra obtida os erros esperado e máximo apresentaram valores próximos de $0.00 \%$, reforçando a idéia de que a amostra apresenta valores bem próximos aos valores de referência. 


\section{Capítulo 6}

\section{Outras Aplicações}

Este capítulo ilustra mais duas aplicações do método de amostragem intencional apresentado nesta dissertação.

A primeira aplicação apresenta um delineamento amostral para medição de audiência televisiva. Trata-se de um estudo mais complexo do que o plano amostral de escolas apresentado no Capítulo 3, pois envolve várias etapas: amostragem estratificada por conglomerados, pesquisa de campo e por fim amostragem intencional. Entretanto, os dois planos amostrais têm como meta selecionar amostras balanceadas com relação à população de interesse, nas diversas variáveis em estudo.

A segunda aplicação apresenta o problema de alocação de tratamento. Estudos deste tipo são muito comuns em ensaios clínicos onde deseja-se analisar diferentes tipos de tratamentos com relação a uma série de variáveis. O objetivo deste plano amostral é formar grupos de tratamento que sejam balanceados entre si, nas diversas variáveis em estudo, garantindo, assim, maior confiabilidade nos resultados das análises comparativas entre os grupos.

\subsection{Plano Amostral para Medição de Audiência de TV}

Para mensurar a audiência televisiva é necessária a instalação de aparelhos especiais nos televisores. Assim, desenhou-se, para a região da Grande São Paulo, uma amostra de domicílios para instalação desses aparelhos, e desta forma estimar com precisão a audiência dos diversos canais do nosso sistema televisivo (TV aberta).

O conjunto de residências deveria resultar em uma amostra com comportamento proporcional, em suas diversas nuanças (variáveis que na opinião dos pesquisadores estavam relacionadas à audiência), 
àquele da população em estudo.

Em uma população com grande heterogeneidade de características fundamentais, uma boa amostra deve possuir representantes de todas as subcategorias. Para podermos satisfazer a todas as restrições logísticas e orçamentárias, utilizou-se a metodologia de amostragem intencional apresentada nesta dissertação.

O IBGE fornece informações relevantes acerca de conjuntos de domicílios denominadas Unidades Censitárias (UCs). Tecnicamente, as UCs podem ser denominadas conglomerados. Na Grande São Paulo o total de conglomerados é de 21240 UCs com variáveis caracterizando o domicílio e seus moradores.

Inicialmente foram estudadas todas as variáveis para se escolher as mais relevantes na seleção das UCs. Com uma análise cuidadosa das correlações e distribuições dos valores foram consideradas as seguintes variáveis para a seleção da amostra de UCs: renda média do domicílio na UC, quantidade de pessoas por UC, variáveis relativas à instrução, quantidade de domicílios na UC e variáveis referentes à idade média dentro de cada domicílio por UC. Nosso procedimento de seleção de residências foi dividido em duas etapas, primeiro selecionamos as UCs e depois os domicílios que fizeram parte da amostra final.

Para a seleção das UCs, primeiramente formaram-se estratos de acordo com a renda média. O próximo passo foi agrupar as UCs de forma que, dentro de cada grupo, estas fossem homogêneas segundo as variáveis descritas acima.

Foram selecionados 10000 domicílios a partir da escolha proporcional das UCs segundo seus respectivos estratos e conglomerados. Devido à homogeneidade dos agrupamentos, foi possível selecionar um pequeno número de UCs para concentrar a escolha dos domicílios definidos para aquele agrupamento.

Para a medição de audiência é necessário, além das variáveis fornecidas pelo IBGE, avaliar outras características dessas residências. Assim, os 10000 domicílios selecionados tiveram, através de pesquisa de campo, suas características exaustivamente estudadas, com ênfase naquelas relacionadas à audiência. Foram coletadas as seguintes informações:

- Condição sócio-econômica do domicílio: através de questões sobre renda e nível de escolaridade dos moradores; 
- Idade dos moradores;

- Condições de cada televisor no domicílio, quanto à localização na residência, tipo de recepção de sinal e posse de controle remoto (em funcionamento);

- Consumo diário de televisão de cada morador, em cada aparelho da residência.

Dentre os 10000 domicílios, selecionou-se uma sub-amostra de residências que melhor reproduzisse, para um conjunto definido de variáveis, as distribuições de freqüências observadas nos domicílios da população da Grande São Paulo. Esta amostra constitui um painel final para a instalação dos 250 aparelhos para monitoramento de audiência.

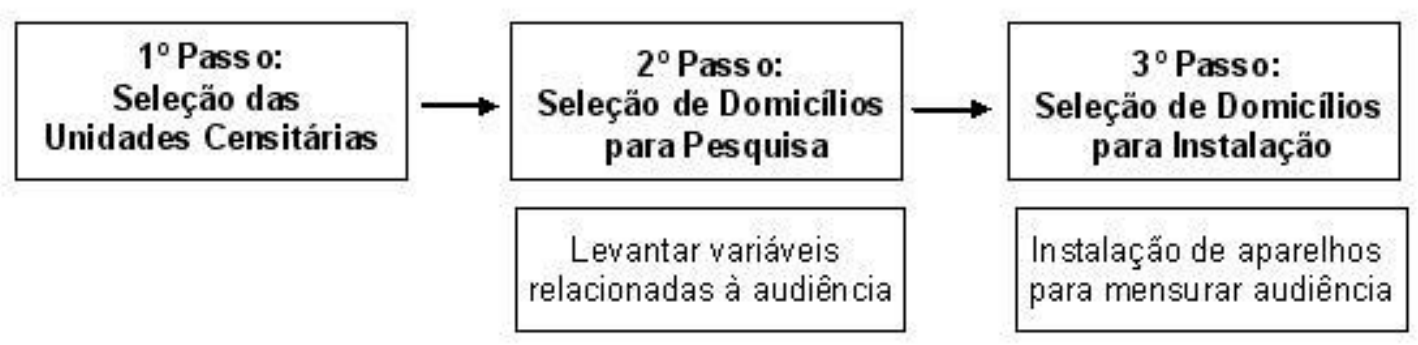

Figura 6.1: Esquema do processo de seleção.

Uma vez que alguns dos domicílios teriam mais do que um televisor monitorado, naturalmente a quantidade de domicílios seria menor do que 250. De fato, a quantidade de domicílios foi um parâmetro calibrado iterativamente ao longo do processo de amostragem. O painel final foi constituído por 232 domicílios, totalizando 250 aparelhos.

As informações sócio-econômicas e populacionais de referência foram obtidas através da Pesquisa Nacional por Amostra de Domicílios (PNAD) referente a 2001 (à época deste trabalho, esses eram os resultados mais recentes). Esta pesquisa, produzida pelo IBGE, possui informações estratificadas das regiões metropolitanas brasileiras. A escolha da PNAD ao invés do Censo Demográfico decorreu do fato de que a PNAD apresenta resultados mais detalhados da distribuição populacional para os aspectos de nosso interesse.

Para a seleção da sub-amostra selecionou-se um conjunto de variáveis populacionais como referência. Para cada variável, estabelecemos cuidadosamente uma categorização buscando um equilíbrio 
entre a adequada discriminação da população e um nível aceitável de domicílios ou indivíduos da amostra em cada categoria.

As variáveis populacionais escolhidas foram:

- Renda bruta domiciliar;

- Faixa etária por sexo;

- Nível de escolaridade (em anos de estudo) das pessoas com mais de 10 anos.

Além das variáveis populacionais, era necessário formar uma sub-amostra com aproximadamente o mesmo comportamento da população em termos de consumo de televisão. A variável escolhida para aferir este comportamento foi o número de horas diárias de televisão por indivíduo. As proporções de referência para essa variável foram obtidas nos 10000 domicílios pesquisados.

Definidas as variáveis e conhecidas as distribuições de freqüências populacionais, utilizou-se o procedimento de amostragem intencional. Desta forma, a seleção foi modelada como um problema de programação linear inteira:

Função objetivo:

$$
\text { Minimizar: } \sum_{j=1}^{m} w_{j}\left(p_{j}+q_{j}\right)
$$

Restrições:

$$
\begin{gathered}
\sum_{i=1}^{n} A_{i, j} x_{i}+p_{j}-q_{j}=d_{j} \\
\sum_{i=1}^{n} x_{i}=K
\end{gathered}
$$

Condições:

$$
x_{i} \in\{0,1\}, \quad p_{j}, q_{j} \in Z^{+}, \quad i=1, \ldots, n, \quad j=1, \ldots, m
$$


Onde,

$n=10000$ (total de domicílios candidatos);

$m=47$ (total de categorias);

$x_{i}$ : Se o i-ésimo domicílio foi selecionado $x_{i}=1$, senão $x_{i}=0$;

$w_{j}$ : Importância relativa (peso) da categoria $\mathrm{j}$ no processo de amostragem;

$p_{j}$ : Variável de folga;

$q_{j}$ : Variável de excesso;

$A_{i j}$ : Categoria $j$ associada ao domicílio $i$. Por exemplo, se a categoria $j$ for associada à variável renda familiar, então $A_{i j}=1$ se e somente se o domicílio $i$ pertencer à faixa de renda $j$. Mas se a categoria $j$ estiver associada a alguma variável de pessoas, como faixa etária, então $A_{i j}=$ quantidade de moradores do domicílio $i$ pertencentes à categoria $j$;

$d_{j}$ : Quantidades esperadas de domicílios / indivíduos na amostra em cada categoria;

K: Quantidade de domicílios a serem selecionados.

As quantidades esperadas (no painel) de domicílios e pessoas em cada categoria de cada variável (metas), foram calculadas a partir das distribuições de referência e do conjunto de 10000 domicílios entrevistados. A função a ser minimizada, similar ao exemplo da amostra de escolas do Ceará, é a soma das diferenças absolutas (erros) entre as quantidades esperadas de domicílios ou pessoas nas categorias das variáveis e as quantidades obtidas nos domicílios selecionados (ver programa GAMS no Apêndice B.1).

Assim, a amostragem intencional produz o painel de domicílios que fornece menor erro em relação às quantidades esperadas nas categorias das variáveis, ou seja, reproduz de forma mais próxima possível os percentuais populacionais das variáveis consideradas relevantes na medição de audiência. 


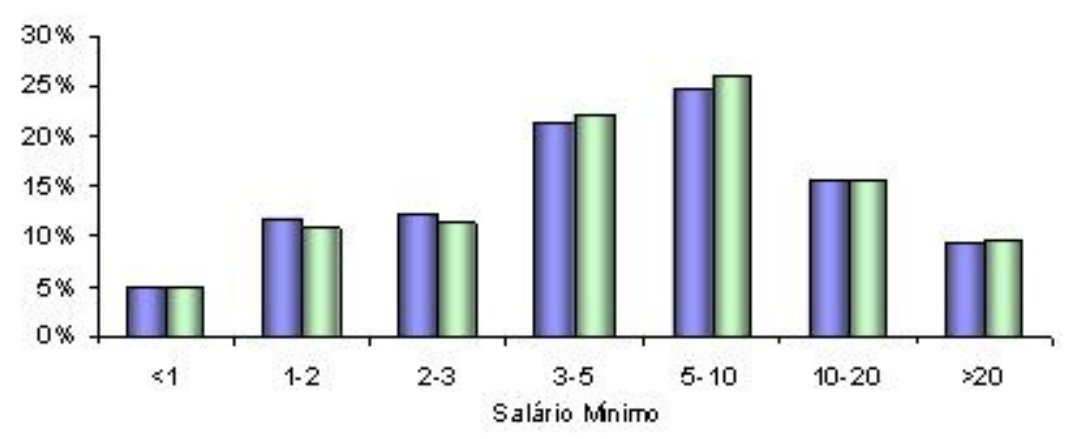

๑ População a Amostra

Figura 6.2: Distribuição de salário mínimo

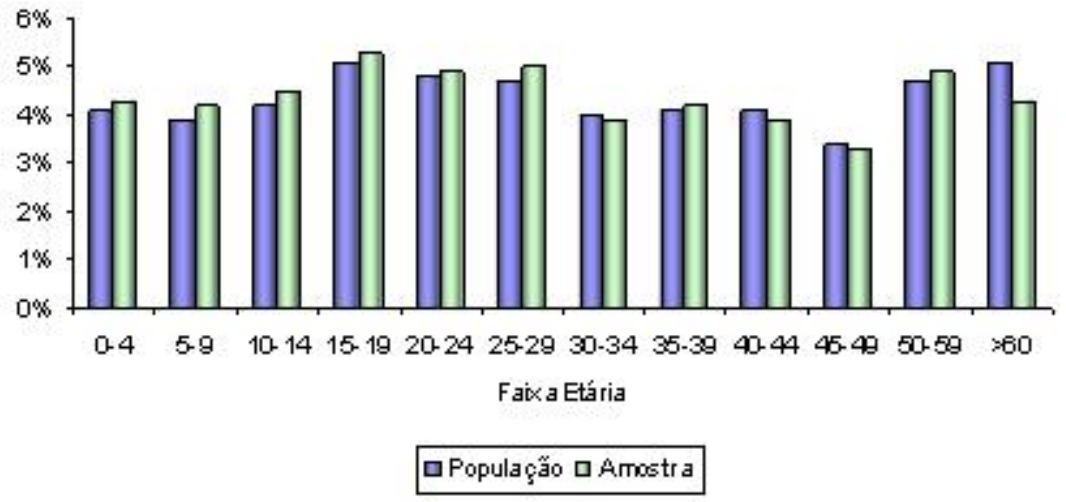

Figura 6.3: Distribuição de mulheres por faixa etária 


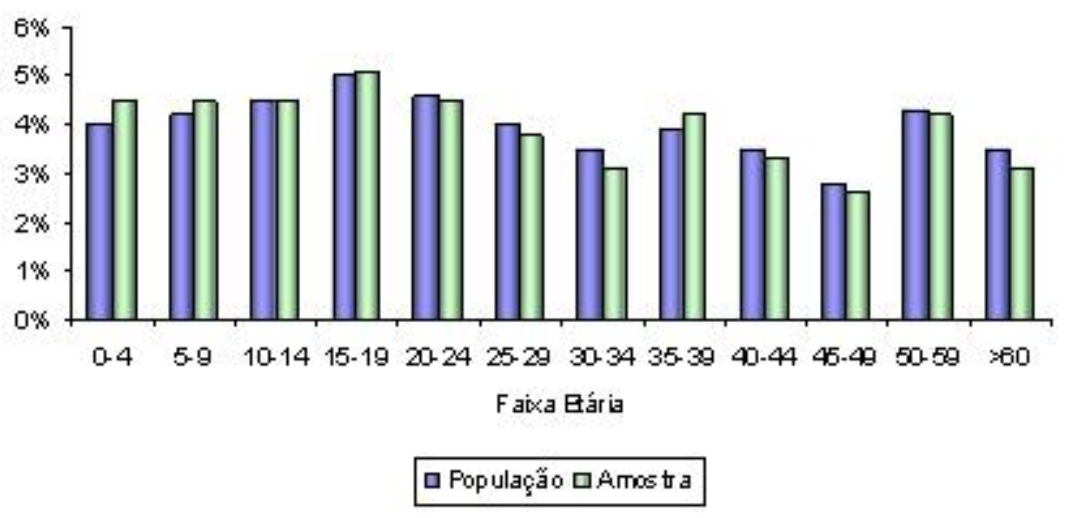

Figura 6.4: Distribuição de homens por faixa etária

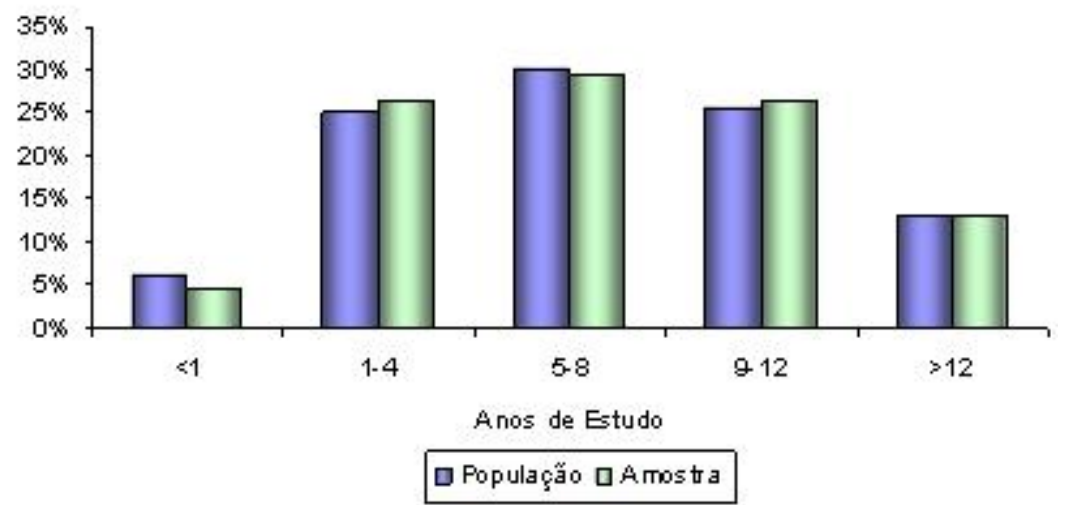

Figura 6.5: Distribuição de pessoas acima de 10 anos por anos de estudo

Os gráficos acima indicam que a distribuição das proporções das classes das variáveis de interesse, na população e na amostra, são bastante próximas entre si.

Para fornecer uma métrica de precisão em cada variável, foram utilizadas as duas medidas de erro amostral definidas no Capítulo 5

Podemos notar, Tabela 6.1, que os erros são baixos, evidenciando que a amostragem intencional produziu uma amostra com comportamento proporcional, àquele da população em estudo. 


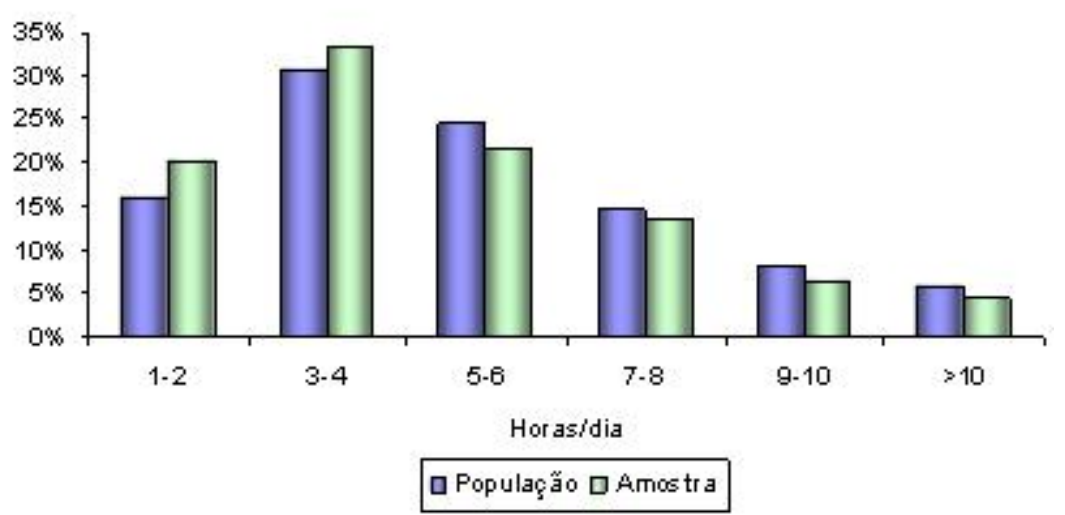

Figura 6.6: Distribuição de pessoas por horas diárias de tv

\begin{tabular}{|c|c|c|}
\hline Variável & Erro Esperado & Erro Máximo \\
\hline \hline Renda do domicílio & $0,74 \%$ & $1,23 \%$ \\
Sexo por faixa etária & $0,23 \%$ & $0,77 \%$ \\
Anos de estudo & $1,10 \%$ & $1,68 \%$ \\
Consumo de TV & $2,50 \%$ & $4,03 \%$ \\
\hline
\end{tabular}

Tabela 6.1: Erros Amostrais.

\subsection{Alocação Dinâmica}

Em ensaios clínicos há geralmente vários fatores de diagnóstico, conhecidos ou desconhecidos, que podem influenciar na resposta do tratamento do paciente. Para comparar grupos de tratamento com a máxima precisão e confiabilidade é de fundamental importância que os grupos de tratamento estejam balanceados com relação a esses fatores de diagnóstico, assim garantimos que qualquer efeito do tratamento seja atribuído exclusivamente ao tratamento em si.

Desenhos de ensaios clínicos que envolvam a escolha de um método de alocação de indivíduos aos tratamentos, podem contribuir para a minimização do viés e garantir uma comparação eficiente. A alocação de indivíduos aos grupos de tratamentos deve possuir duas características: aleatoriedade e balanceamento entre os grupos com relação aos fatores de diagnóstico.

A aleatorização reduz o viés de seleção e garante comparabilidade com relação a fatores conhecidos e desconhecidos que podem afetar a variável resposta. Além disso, a aleatorização serve como base para a utilização dos métodos estatísticos de análise. Por sua vez, o balanceamento das variáveis 
de diagnóstico assegura maior credibilidade ao estudo [14], já que ao melhorar o balanceamento das variáveis de diagnóstico também aumentamos potencialmente o poder estatístico da análise.

O método mais simples para alocação de pacientes é a utilização da aleatorização simples, na qual cada indivíduo tem a mesma probabilidade $\frac{1}{N}$ de ser alocado a qualquer um $\operatorname{dos} N$ tratamentos. A metodologia de aleatorização foi desenvolvida no século XIX [15] e descrita mais adiante em $1930[1,11]$, mas tornou-se uma ferramenta essencial para pesquisas somente em meados de 1940.

Este método claramente satisfaz o critério de aleatoriedade, uma vez que garante que a alocação dos tratamentos não seja baseada nos fatores de diagnóstico dos indivíduos, prevenindo o pesquisador de, conscientemente ou inconscientemente, alocar um mesmo tipo de indivíduo a um determinado tratamento. Porém, pode ocorrer desbalanceamento considerável entre os números dos grupos tratado e controle. A aleatorização garantirá, em grandes ensaios clínicos, balanceamento entre os grupos com relação às variáveis de diagnóstico mais relevantes. Entretanto, pode haver desbalanceamento significativo em um ou mais fatores se o ensaio é pequeno ou se houver muitas variáveis a serem controladas [16].

Pelo exposto acima, a aleatorização simples não é muito empregada na prática. Por outro lado, o método de estratificação em blocos é largamente utilizado na alocação de tratamentos. Este método consiste na alocação de pacientes nos estratos formados pelos níveis das variáveis de diagnóstico em cada tratamento. Porém, para estudos com muitos fatores a serem controlados, a quantidade de estratos pode se tornar muito grande. Por exemplo, se um estudo possuir 3 fatores com 4 níveis cada um, a quantidade de estratos será $4^{3}=64$. Ao menos que o ensaio seja grande o suficiente, muitos desses estratos não conteriam pacientes. Assim a estratificação pode acarretar em desbalanceamento dos fatores, uma vez que muitos blocos podem permanecer incompletos [19].

Notamos que na maioria dos métodos usuais de amostragem os requisitos de aleatoriedade e balanceamento entram em conflito.

Muitos outros métodos foram desenvolvidos como uma alternativa à aleatorização estratificada, por exemplo, o plano de urnas proposto por Atkinson (1982) [2] e Begg and Iglewicz (1980) [4], porém são raramente utilizados na prática.

Em 1974, Taves [17] desenvolveu um método de estratificação adaptável utilizando minimização. Posteriormente, Pocock and Simon [16] apresentaram uma generalização do método de Taves. Este método considera a distribuição dos fatores de diagnóstico de pacientes já alocados em um ensaio e 
aloca um novo paciente a um determinado tratamento, de tal forma que minimize o desbalanceamento entre os grupos em termos das variáveis de interesse. Este procedimento pode ser tratado como uma forma de amostragem intencional, pois em vez de produzir uma alocação aleatória, produz uma alocação intencional ótima dos indivíduos aos grupos de tratamento.

Assim, nesta seção é apresentado o método de minimização para a alocação seqüencial, proposto por Pocock e Simon (1975).

Por simplicidade, considere um ensaio clínico com 2 grupos de tratamento (tratado e controle). Antes de se iniciar a aplicação do método de alocação é necessário definir alguns parâmetros:

- Escolher a medida para avaliar o desbalanceamento entre os tratamentos para um dado fator de diagnóstico $(D)$. Mensurar o desbalanceamento em dois cenários diferentes: alocando o novo paciente no grupo tratado e depois no grupo controle;

- Selecionar o método para calcular o desbalanceamento total $(G)$, considerando todas as variáveis de diagnóstico, também nos dois cenários;

- Especificar os pesos utilizados no cálculo do desbalanceamento total $(W)$ para representar a importância relativa das variáveis de diagnóstico;

- Definir a probabilidade $(p)$ com a qual o indivíduo será alocado no grupo de tratamento com menor desbalanceamento total.

O nível de desbalanceamento entre os grupos de tratamento para um dado nível de uma variável de diagnóstico $(D)$ pode ser calculado de várias formas. O método mais intuitivo é calcular o desvio padrão ou variância do número de pacientes em cada tratamento. Quando há apenas 2 tratamentos, o desvio padrão é equivalente à diferença absoluta entre os grupos.

O método mais simples para combinar o desbalanceamento de todas as variáveis de diagnóstico $(G)$ é calcular a sua soma. Há casos em que alguns fatores possuem uma relação mais forte com a variável resposta do que outros. Neste caso, deve-se atribuir pesos $(W)$ maiores a essas variáveis para refletir sua importância relativa. O método de estratificação adaptável proposto por Taves (1974) é similar ao apresentado por Pocock and Simon (1975), porém com $p=1$, ou seja, o paciente sempre é alocado no tratamento que resulta em menor desbalanceamento. 
Para melhor ilustrar considere um ensaio clínico com 2 grupos de tratamento e com as seguintes variáveis de diagnóstico: sexo, idade e fator de risco. Neste caso, utilizamos como medida de desbalanceamento entre os grupos de tratamento a métrica: $d_{i}=\left|N_{i A}-N_{i B}\right|$, onde $N_{i A}$ é o número de indivíduos alocados no tratamento $A$ na i-ésima variável de diagnóstico e $N_{i B}$ é o número de indivíduos alocados ao tratamento $B$ na i-ésima variável de diagnóstico. Como medida total de desbalanceamento utilizamos a soma de $d_{i}$, com todas as variáveis de diagnóstico com o mesmo peso $\left(w_{i}=1\right)$. Como probabilidade de alocação definimos $p_{1}=0,75$.

Sessenta e um indivíduos já foram alocados aos tratamentos e o próximo paciente a entrar no ensaio é uma jovem mulher com alto fator de risco. Alocando o novo indivíduo no tratamento A teríamos um desbalanceamento de $5(|17-14|+|17-15|+|10-10|)$, e alocando no tratamento B resultaria em um desbalanceamento total de $3(|16-15|+|16-16|+|9-11|)$. O desbalanceamento total entre os grupos seria, então, minimizado se o novo paciente fosse alocado ao tratamento B, que neste caso ocorreria com probabilidade 0,75 .

\begin{tabular}{|c|c|c|c|}
\hline Fatores de Diagnóstico & Tratamento A & Tratamento B & Desbalanceamento \\
\hline \hline Maculino & 15 & 16 & 1 \\
Feminino & 16 & 14 & 2 \\
\hline Jovem & 16 & 15 & 1 \\
Velho & 15 & 15 & 0 \\
\hline Alto & 9 & 10 & 1 \\
Médio & 10 & 10 & 0 \\
Baixo & 12 & 10 & 2 \\
\hline
\end{tabular}

Tabela 6.2: Medida de desbalanceamento entre os tratamentos.

O aspecto aleatório na alocação dos tratamentos ainda é preservado pela seqüência aleatória na qual os pacientes chegam para inclusão no ensaio clínico. A propriedade mais importante no esquema de alocação aqui apresentado é a lógica que permite a qualquer um provar que o esquema foi seguido.

Uma limitação deste procedimento é que é necessário conhecer o valor de cada fator de diagnóstico, para cada paciente participante do estudo, antes de decidir onde alocá-lo. Conseqüentemente, valores de fatores de diagnóstico que dependem de longas avaliações, terminando depois de iniciado o tratamento, não podem ser incluídos no modelo. Outro ponto é a determinação dos pesos associados às variáveis de diagnóstico, pois trata-se de uma decisão arbitrária. Mas tal fato não favorece qualquer tendência de alocação que possa resultar em um desbalanceamento que favoreça qualquer resultado de resposta ao tratamento. 


\section{Capítulo 7}

\section{Considerações Finais}

Como visto nos Capítulos 5 e 6 o procedimento amostral descrito nesta dissertação pode ser adaptado de forma simples para diferentes delineamentos de estudos.

As aplicações apresentadas indicam que a metodologia produziu amostras balanceadas, nas diversas características de interesse.

Os procedimentos inferenciais padrão baseiam-se na suposição de aleatoriedade. Entretanto, tal fato só é verdadeiro em procedimentos que utilizam aleatorização pura. Em planos amostrais com otimização, algumas unidades amostrais são mais prováveis de se selecionar do que outras.

Muitos autores acreditam que, para os propósitos práticos, os testes convencionais apresentam propriedades satisfatórias se os fatores de balanceamento forem considerados como covariáveis nas análises. Além disso, podemos considerar que a componente aleatória fica por conta da seleção dentro dos grupos que sofreram o controle pelo conhecimento dos parâmetros correlatos. 


\section{Apêndice A}

\section{Plano Amostral de Escolas}

\section{A.1 Municípios Participantes da Pesquisa}

\begin{tabular}{|l|l|}
\hline AMONTADA & JIJOCA DE JERICOACARA \\
AQUIRAZ & JUAZEIRO DO NORTE \\
ARACATI & JUCÁS \\
ARACOIABA & LIMOEIRO DO NORTE \\
ARATUBA & MARACANAU \\
BARBALHA & MARANGUAPE \\
BEBERIBE & MONSENHOR TABOSA \\
BREJO SANTO & NOVA OLINDA \\
CAUCAIA & PACATUBA \\
CRATEUS & PACOTI \\
CRATO & PACUJA \\
CROATA & PEDRA BRANCA \\
EUSEBIO & PEREIRO \\
FARIAS BRITO & POTIRETAMA \\
FORTALEZA & QUIXERAMOBIM \\
GRANJA & RUSSAS \\
GUAIUBA & SALITRE \\
HORIZONTE & SAO GONÇALO DO AMARANTE \\
IGUATU & SOBRAL \\
IRACEMA & TARRAFAS \\
ITAITINGA & TAUÁ \\
ITAPAJE & TEJUÇUOCA \\
ITAPIUNA & TIANGUA \\
ITAREMA & TURURU \\
ITATIRA & \\
\hline
\end{tabular}

Tabela A.1: Municípios participantes da pesquisa. 
Apêndice 2

\section{A.2 Programa GAMS}

O programa em GAMS [5] abaixo seleciona, via amostragem intencional, o conjunto de escolas dentre os 49 municípios participantes da pesquisa. Vale ressaltar que os bancos de dados são confidenciais e, portanto, os valores apresentados no programa são fictícios e têm a única finalidade de ilustrar os conceitos apresentados neste trabalho.

\section{SETS}

I escola / i1, i2, i3, i4, i5, ..., i2557 /

J categoria / j1, j2, j3, j4, j5, .., j20 /

K municípios / k1, k2, k3, k4, k5, .., k49 /

TABLE M(I,J) contagem de alunos por escola x categoria

$\begin{array}{llllllll}\mathrm{i} / \mathrm{j} & \mathrm{j} 1 & \mathrm{j} 2 & \mathrm{j} 3 & \mathrm{j} 4 & \mathrm{j} 5 & \ldots & \mathrm{j} 20 \\ \mathrm{i} 1 & 45 & 0 & 0 & 45 & 0 & \ldots & 0 \\ \mathrm{i} 2 & 11 & 0 & 0 & 11 & 0 & \ldots & 0 \\ \mathrm{i} 3 & 41 & 0 & 0 & 0 & 0 & \ldots & 0 \\ \mathrm{i} 4 & 84 & 0 & 0 & 0 & 84 & \ldots & 0 \\ \mathrm{i} 5 & 37 & 0 & 0 & 0 & 37 & \ldots & 0 \\ \ldots & \ldots & \ldots & \ldots & \ldots & \ldots & \ldots & \ldots \\ \mathrm{i} 2557 & 94 & 0 & 94 & 0 & 0 & \ldots & 0\end{array}$

TABLE B(I,K) pertinência escola x município

$\begin{array}{llllllll}\mathrm{i} / \mathrm{k} & \mathrm{k} 1 & \mathrm{k} 2 & \mathrm{k} 3 & \mathrm{k} 4 & \mathrm{k} 5 & \ldots & \mathrm{k} 49 \\ \mathrm{i} 1 & 0 & 0 & 0 & 0 & 1 & \ldots & 0 \\ \mathrm{i} 2 & 0 & 0 & 0 & 0 & 1 & \ldots & 0 \\ \mathrm{i} 3 & 0 & 0 & 1 & 0 & 0 & \ldots & 0 \\ \mathrm{i} 4 & 0 & 0 & 1 & 0 & 0 & \ldots & 0 \\ \mathrm{i} 5 & 0 & 0 & 0 & 1 & 0 & \ldots & 0 \\ \ldots & \ldots & \ldots & \ldots & \ldots & \ldots & \ldots & \ldots \\ \mathrm{i} 2557 & 0 & 1 & 0 & 0 & 0 & \ldots & 0\end{array}$


WA peso da selecao de municípios voluntários /1.000000/

SCALARS WX peso do número de escolas na amostra /0.010000/

ESM número mínimo de escolas a ser selecionada no município /4/

MS ; número de municípios a serem selecionados /49/;

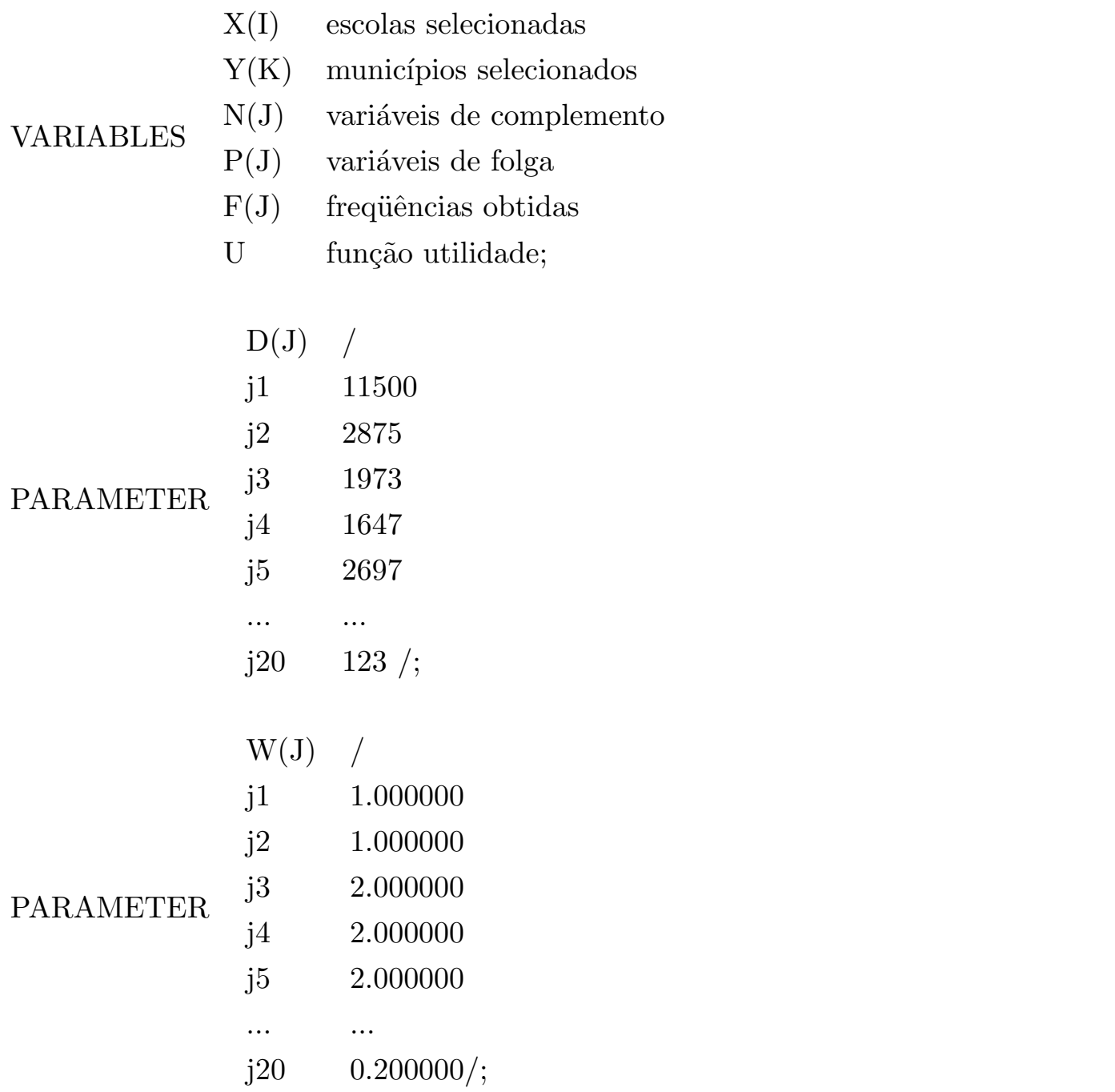




$\begin{array}{lll} & \mathrm{AD}(\mathrm{K}) & / \\ \mathrm{k} 1 & 1 \\ \mathrm{k} 2 & 1 \\ \text { PARAMETER } & \mathrm{k} 3 & 1 \\ & \mathrm{k} 4 & 1 \\ & \mathrm{k} 5 & 1 \\ & \ldots & \ldots \\ \mathrm{k} 49 & 1 / ;\end{array}$

BINARY VARIABLES X, Y;

POSITIVE VARIABLES N, P;

\begin{tabular}{|c|c|c|}
\hline \multirow{5}{*}{ EQUATIONS } & UTIL & função objetivo \\
\hline & QUANTMUN & restrição do número de municípios selecionados \\
\hline & $\operatorname{DEPEND}(\mathrm{I})$ & somente podem ser selecionadas escolas nos municípios selecionados \\
\hline & $\operatorname{MINESC}(\mathrm{K})$ & somente podem ser selecionadas escolas nos municípios selecionados \\
\hline & GOAL $(J)$ & metas de freqüências; \\
\hline UTIL & \multicolumn{2}{|c|}{$\begin{aligned} U=E= & S U M(J, W(J) *(N(J)+P(J)))+W(X) * S U M(I, X(I)) \\
& -W A * S U M(K, A D(K) * Y(K)) ;\end{aligned}$} \\
\hline QUANTMUN & \multicolumn{2}{|c|}{$S U M(K, Y(K))=E=M S$} \\
\hline DEPEND(I) & \multicolumn{2}{|c|}{$S U M(K, B(I, K) * Y(K))=G=X(I)$} \\
\hline GOAL $(J)$ & \multicolumn{2}{|c|}{$S U M(I, M(I, J) * X(I))+N(J)-P(J)=E=D(J)$} \\
\hline
\end{tabular}

MODEL SELESC /ALL/;

option iterlim $=500000$;

option optcr $=0.010000$;

SOLVE SELESC USING RMIP MINIMIZING U ;

DISPLAY X.L, Y.L, U.L ;

FILE F1 /esc.out/ ; 
$\mathrm{F} 1 . \mathrm{AP}=0 ;$

PUT F1;

LOOP((I), PUT X.L(I):4:0 /);

PUT F1;

$\mathrm{F} . \mathrm{L}(\mathrm{J})=\mathrm{SUM}(\mathrm{I}, \mathrm{M}(\mathrm{I}, \mathrm{J}) * \mathrm{X} . \mathrm{L}(\mathrm{I}))$;

FILE F2 /freqesc.out/ ;

$\mathrm{F} 2 . \mathrm{AP}=0$;

PUT F2;

$\operatorname{LOOP}((J)$, PUT F.L(J):7:0 /);

PUT F2;

FILE F3 /munic.out/ ;

$\mathrm{F} 3 . \mathrm{AP}=0$;

PUT F3;

$\operatorname{LOOP}((\mathrm{K})$, PUT Y.L(K):4:0 /);

PUT F3; 


\section{Apêndice B}

\section{Plano Amostral para Medição de Audiência de TV}

Este apêndice apresenta o programa GAMS [5] utilizado na seleção de domicílios para medição de audiência televisiva. Vale ressaltar que os bancos de dados são confidenciais e, portanto, os valores apresentados no programa são fictícios e têm a única finalidade de ilustrar os conceitos apresentados neste trabalho.

\section{B.1 Programa GAMS}

SETS

I domicílio / i1, i2, i3, i4, i5, ..., i6739 /

J categoria / p1, p2, p3, p4, p5, .., p47/

TABLE M(I,J) relação domicílio x categoria

$\begin{array}{llllllll}\mathrm{i} / \mathrm{p} & \mathrm{p} 1 & \mathrm{p} 2 & \mathrm{p} 3 & \mathrm{p} 4 & \mathrm{p} 5 & \ldots & \mathrm{p} 47 \\ \mathrm{i} 1 & 0 & 0 & 0 & 0 & 1 & \ldots & 0 \\ \mathrm{i} 2 & 1 & 0 & 0 & 4 & 0 & \ldots & 0 \\ \mathrm{i} 3 & 1 & 0 & 0 & 0 & 3 & \ldots & 0 \\ \mathrm{i} 4 & 0 & 0 & 0 & 0 & 0 & \ldots & 0 \\ \mathrm{i} 5 & 0 & 1 & 0 & 5 & 0 & \ldots & 1 \\ \ldots & \ldots & \ldots & \ldots & \ldots & \ldots & \ldots & \ldots \\ \mathrm{i} 6739 & 1 & 0 & 0 & 0 & 2 & \ldots & 3\end{array}$

SCALARS Q número de produtos lançados /270/ 


\begin{tabular}{|c|c|c|}
\hline \multirow{5}{*}{ VARIABLES } & $\mathrm{X}(\mathrm{I})$ & domicílios selecionados \\
\hline & $\mathrm{N}(\mathrm{J})$ & variáveis de complemento \\
\hline & $\mathrm{P}(\mathrm{J})$ & variáveis de folga \\
\hline & $\mathrm{F}(\mathrm{J})$ & freqüências obtidas \\
\hline & $\mathrm{U}$ & função utilidade; \\
\hline \multirow{8}{*}{ PARAMETER } & $\mathrm{D}(\mathrm{J})$ & / \\
\hline & p1 & 13.000000 \\
\hline & $\mathrm{p} 2$ & 33.000000 \\
\hline & p3 & 35.000000 \\
\hline & $\mathrm{p} 4$ & 56.000000 \\
\hline & $\mathrm{p} 5$ & 65.000000 \\
\hline & $\cdots$ & $\cdots$ \\
\hline & $\mathrm{p} 47$ & $250.000000 / ;$ \\
\hline \multirow{8}{*}{ PARAMETER } & $\mathrm{W}(\mathrm{J})$ & / \\
\hline & p1 & 1.000000 \\
\hline & p2 & 1.000000 \\
\hline & p3 & 1.000000 \\
\hline & $\mathrm{p} 4$ & 1.000000 \\
\hline & $\mathrm{p} 5$ & 1.000000 \\
\hline & $\ldots$ & $\ldots$ \\
\hline & $\mathrm{p} 47$ & $0.200000 /$ \\
\hline \multirow{8}{*}{ PARAMETER } & $\mathrm{X} 0(\mathrm{I})$ & / \\
\hline & i1 & 0 \\
\hline & $\mathrm{i} 2$ & 0 \\
\hline & i3 & 1 \\
\hline & i4 & 0 \\
\hline & i5 & 0 \\
\hline & $\cdots$ & $\cdots$ \\
\hline & i6739 & $1 / ;$ \\
\hline
\end{tabular}

BINARY VARIABLES X; 
POSITIVE VARIABLES N, P;

$\begin{array}{cll} & \begin{array}{l}\text { UTILITY } \\ \text { QUANTITY }\end{array} & \begin{array}{l}\text { função objetivo } \\ \text { restrição do número de domicílios selecionados } \\ \text { domicílios pré selecionados } \\ \text { PRESELEC } \\ \text { GOAL }(\mathrm{J})\end{array} \\ & \begin{array}{l}\text { metas de freqüências; } \\ \text { UTILITY }\end{array} \\ \text { QUANTITY } & S U M(I, X(I))=L=Q ; \\ \text { PRESELEC } & S U M(I, X 0(I) * X(I))=G=243 ; \\ \text { GOAL }(\mathrm{J}) & S U M(I, M(I, J) * X(I))+N(J)-P(J)=E=D(J) ;\end{array}$

MODEL SETCOV / ALL/ ;

option iterlim $=100000$;

option optcr $=0.010000$;

SOLVE SETCOV USING MIP MINIMIZING U ;

DISPLAY X.L, U.L ;

FILE F1 /x.out/ ;

$\mathrm{F} 1 . \mathrm{AP}=0$;

PUT F1;

PUT 'Selec $=[\%$

LOOP((I), PUT X.L(I):4:0 /);

PUT '];'

PUT F1;

$\mathrm{F} . \mathrm{L}(\mathrm{J})=\operatorname{SUM}(\mathrm{I}, \mathrm{M}(\mathrm{I}, \mathrm{J}) * \mathrm{X} . \mathrm{L}(\mathrm{I}))$;

FILE F2 /mx.out/ ;

$\mathrm{F} 2 . \mathrm{AP}=0 ;$ 
PUT F2;

$\mathrm{PUT}$ ' $\mathrm{F}=[\%$

$\operatorname{LOOP}((J)$, PUT F.L(J):4:0 /);

PUT '];'

PUT F2; 


\section{Referências Bibliográficas}

[1] J. B. Amberson, B. T. McMahon, and M. A. Pinner, A clinical trial of socrysin in pulmonary tuberculosis, Amer Rev Tuber 24 (1931), 401-435.

[2] A. C. Atkinson, Optimum biased coin design for sequential clinical trials with prognostic factors, Biometrika 69 (1982), 61-67.

[3] M. S. Bazaraa, J. J. Jarvis, and H. D. Sherali, Linear programming and network flows, second ed., John Wiley and Sons, New York, 1977.

[4] C. B. Begg and B. A. Iglewicz, A treatment allocating procedure for sequential clinical trials, Biometrics 36 (1980), 81-90.

[5] A. Brooke, D. A. Kendrick, and A. Meeraus, Gams: sistema geral de modelagem algébrica, first ed., Edgard Blucher, São Paulo, 1997.

[6] V. Chvátal, Linear programming, second ed., W. H. Freeman, New York, 1983.

[7] W. G. Cochran, Sampling techniques, third ed., John Wiley and Sons, New York, 1977.

[8] G. B. Dantzig, Linear programming and extensions, third ed., Princeton University Press, Princeton, 1963.

[9] G. B. Dantzig and M. N. Thapa, Linear programming, second ed., Springer, New York, 1998.

[10] H. Bolfarine e W. O. Bussab, Elementos de amostragem, first ed., Edgard Blücher, São Paulo, 2005 .

[11] R. A. Fisher, Randomization, and an old enigma of card play, Mathematical Gazette 18 (1934), $294-7$.

[12] R. J. Jessen, Statistical survey techniques, first ed., John Wiley and Sons, New York, 1978.

[13] L. Kish, Survey sampling, third ed., John Wiley and Sons, New York, 1965. 
[14] D. J. McEntegart, The pursuit of balance using stratified an dynamic randomization techniques: An overview, Drug Information Journal 37 (2003), 293-309.

[15] C. S. Pierce and J. Jastrow, On small diferences of sensation, Memirs of the National Academy of Sciences 3 (1885), 75-83.

[16] S. J. Pocock and R. Simon, Sequential treatment assignment with balancing for prognostic factors in the controlled clinical trial, Biometrics 31 (1975), no. 1, 103-115.

[17] D. R. Taves, Minimization: a new method of assigning patients to treatment and control groups, Clinical Pharmacology and Therapeutics 15 (1974), 443-453.

[18] UNICEF, Fundo das nações unidas para a infância, http://www.unicef.org/brazil/selo.htm.

[19] C. J. Weir and K. R. Lees, Comparison of stratification and adaptive methods for treatment allocation in an acute stroke clinical trial, Statistics in Medicine 22 (2003), no. 1, 705-726.

[20] L. A. Wolsey, Integer programming, first ed., John Wiley and Sons, New York, 1998.

[21] S. Zionts, Linear and integer programming, first ed., Prentice Hall, New Jersey, 1974. 


\section{Índice Remissivo}

aditividade, 16

amostragem, 3

aleatória simples, 5

estratificada, 5

intencional, 9

por conglogmerados, 7

sistemática, 6

Branch and Bound, 31

coeficientes

custo, 15

tecnológicos, 15

degeneração, 23, 27

determinístico, 16

divisibilidade, 16

erros

amostrais, 4

não amostrais, 5

forma

canônica, 23, 26

padrão, 15, 22

função objetivo, 14, 19

gradiente, 20

Grupo UNICEF, 9

pivoteamento, 22, 23

programação linear, 13, 14, 16

inteira, 16, 28 inteira binária, 28

inteira mista, 28

inteira pura, 28

proporcionalidade, 16

Simplex

algoritmo, 22, 27, 30, 31

método, 21, 26, 30, 31

sistemas de referência, 3

solução

ótima, 14, 31

básica, 23, 24

viável, 14, 19

variáveis

de folga, 15

artificiais, 26, 27

básicas, 23

decisão, 15

não básicas, 23, 26 